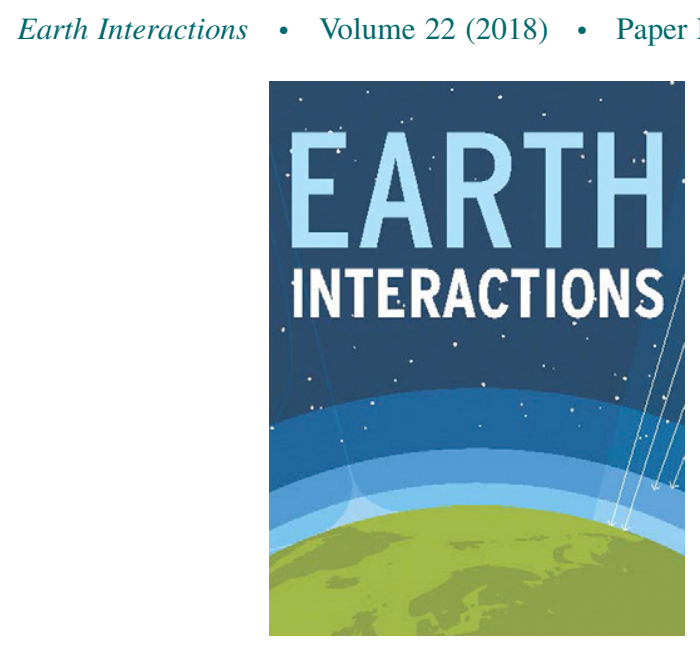

\title{
Simulated Sensitivity of Urban Green Infrastructure Practices to Climate Change
}

\section{Saumya Sarkar ${ }^{\mathrm{a}}$ and Jonathan B. Butcher}

Tetra Tech, Inc., Research Triangle Park, North Carolina

\section{Thomas E. Johnson and Christopher M. Clark}

U.S. Environmental Protection Agency, Office of Research and Development, Washington, D.C.

Received 28 June 2017; in final form 27 March 2018

\begin{abstract}
Climate change is likely to alter the quantity and quality of urban stormwater, presenting a risk to water quality and public health. How might stormwater management practices need to change to address future climate? Answering requires understanding how management practices respond to climate forcing. Traditional "gray" stormwater design employs engineered structures, sized based on assumptions about future rainfall, which have limited flexibility once built. Green infrastructure (GI) uses vegetation, soil, and distributed structures to manage rainwater where it falls and may provide greater flexibility for adaptation. There is, however, uncertainty about how a warmer climate may affect performance of different types of GI. This study uses the
\end{abstract}

Supplemental information related to this paper is available at the Journals Online website: https://doi.org/10.1175/EI-D-17-0015.s1.

${ }^{a}$ Corresponding author: Saumya Sarkar, saumya.sarkar@tetratech.com

DOI: 10.1175/EI-D-17-0015.1 
Earth Interactions - Volume 22 (2018) - Paper No. 13 • Page 2

hydrologic and biogeochemical watershed model, Regional Hydro-Ecologic Simulation System (RHESSys), to investigate sensitivity of different GI practices to climate. Simulations examine 36 urban "archetypes" representing different development patterns (at the city block scale) of typical U.S. cities, 11 regional climatic settings, and a range of mid-twenty-first-century scenarios based on downscaled climate model output. Results suggest regionally variable effects of climate change on the performance of GI practices for water quantity, water quality, and carbon sequestration. GI is able to mitigate most projected future increases in surface runoff, while bioretention can mitigate increased nitrogen yield at nine of 11 sites. Simulated changes in carbon balance are small, while local evaporative cooling can be substantial. Given uncertainty in the local expression of future climate, infrastructure design should emphasize flexibility and robustness to a range of future conditions.

KEYWORDS: Climate models; Hydrologic models; Planning

\section{Introduction}

Increased impervious surfaces and enhanced connectivity of drainage networks in urban areas lead to higher stormwater runoff volume and peaks and enhanced pollutant loads (e.g., Walsh et al. 2005). A variety of best management practices (BMPs) can be implemented to reduce the adverse impacts of urban stormwater. Traditional "gray" stormwater management infrastructure uses single-purpose, hard structures, including detention basins and storm sewers, to convey runoff. These engineered solutions can be effective, but can be difficult to modify to meet changing conditions. Conversely, green infrastructure (GI) uses vegetation and soil to manage rainwater near where it falls. GI also often provides cobenefits (e.g., mitigation of urban heating, carbon and nitrogen sequestration, and habitat provision), and flexibility as compared to engineered, hard structures. A review of 17 case studies of low impact development (LID) incorporating GI suggests that GI practices are both environmentally and economically beneficial (U.S. EPA 2007). The review also concludes that barring a few exceptions, LID methods generally result in cost savings of $15 \%$ to $80 \%$.

Anticipated future climate includes warming temperature and changes in the amount and intensity of precipitation (IPCC 2014). If realized, these changes will have direct effects on stormwater and may require adaptation of the existing stormwater infrastructure. Effects are likely to vary significantly in different regions of the United States. Infrastructure sensitivity to climate change depends first on changes to magnitude and frequency of peak flows, which may result from changes in rainfall intensity or from alterations to the snowmelt regime (e.g., Hamlet and Lettenmaier 2007). One of the most important determinants in design of stormwater infrastructure is climate, followed by the amount of impervious area, soil type, vegetative cover, and slope.

Arisz and Burrell (2006) discuss climate sensitivity for the "urban minor drainage system" (which includes both gray and green infrastructure) and emphasize the difficulties in expanding engineered infrastructure or introducing large, new green spaces into existing urban footprints. Gill et al. (2007) also note similar constraints. A viable alternative is provided by the use of distributed GI. GI design components that increase the resilience of the drainage system to climate change include use of permeable and porous pavement, green roofs, rainwater harvesting, and bioretention/infiltration. 
Earth Interactions - Volume 22 (2018) • Paper No. 13 • Page 3

In addition to addressing water quantity and quality, GI provides cobenefits, including carbon sequestration and other ecosystem services that benefit local communities. For example, urban areas have higher summer air temperatures than surrounding open areas due to replacement of transpiring vegetation with hard surfaces (the urban heat island effect; e.g., Taha 1997; Pielke 2013), and GI can help mitigate this effect (Kleerekoper et al. 2012). Gill et al. (2007) have found that adoption of green roofs could provide a dramatic reduction in future maximum urban surface air temperatures. Simulations using the U.S. Forest Service i-Tree model indicate that urban trees store large quantities of carbon, remove large amounts of air pollution, intercept precipitation, provide local cooling, and reduce energy use of buildings (https://www.nrs.fs.fed.us/data/urban/; Wang et al. 2008). In an i-Tree model for Worcester, Massachusetts, Filipovic et al. (2016) show that increase in tree canopy cover results in a decrease in stormwater volume and rate.

Pataki et al. (2011) quantified the range of biogeochemical processes in urban green infrastructure, including services such as offsetting greenhouse gas emissions, removing air and water pollutants, and improving public health. Of the various ecosystem services associated with GI, they conclude that the potential for $\mathrm{C}$ sequestration and air quality mitigation is low, the effect on net greenhouse gas (GHG) emissions is uncertain, and the potential magnitude of local cooling, stormwater volume reduction, and water quality mitigation is high.

The "green" part of GI is dependent on plant growth and soil microbial processes, all of which are sensitive to changes in temperature, precipitation, and the water balance. Stormwater managers face questions about what type, where, and how much GI is needed to meet water quality goals under both current and future conditions. GI provides benefits that could help communities adapt and become more resilient to future change, but different types of GI may respond to change in different ways. In this study, we incorporate GI into existing typical urban layouts using a biogeochemical model to investigate how the performance of GI might be affected by climate. Performance of GI is quantified in terms of ability to mitigate stormwater runoff, reduce nutrient losses, and provide urban cooling effects. We examine the effectiveness of different GI practices, including the adjustments that may be necessary to compensate for potential future changes in rainfall and temperature in different urban settings.

\section{Methods}

\subsection{The Regional Hydro-Ecologic Simulation System (RHESSys)}

In this study, we use the mechanistic, hydrologic, and biogeochemical model, Regional Hydro-Ecologic Simulation System (RHESSys; Tague and Band 2004). RHESSys is a hydro-ecological modeling framework designed to simulate water, carbon, and nitrogen fluxes over time, incorporating a full representation of plant growth (canopy, stem, and roots), litter, and soil processes at a user-defined spatial scale. The hierarchical and distributed elements of a RHESSys model (shown in Figure 1) consist of a watershed, zones, hillslopes, patches, and strata. Zones are areas of similar climate, while hillslopes define areas that drain to a single point. Patches are high-resolution spatial units where physical processes like infiltration, soil moisture processing, and litter layer dynamics are simulated. Strata are the 


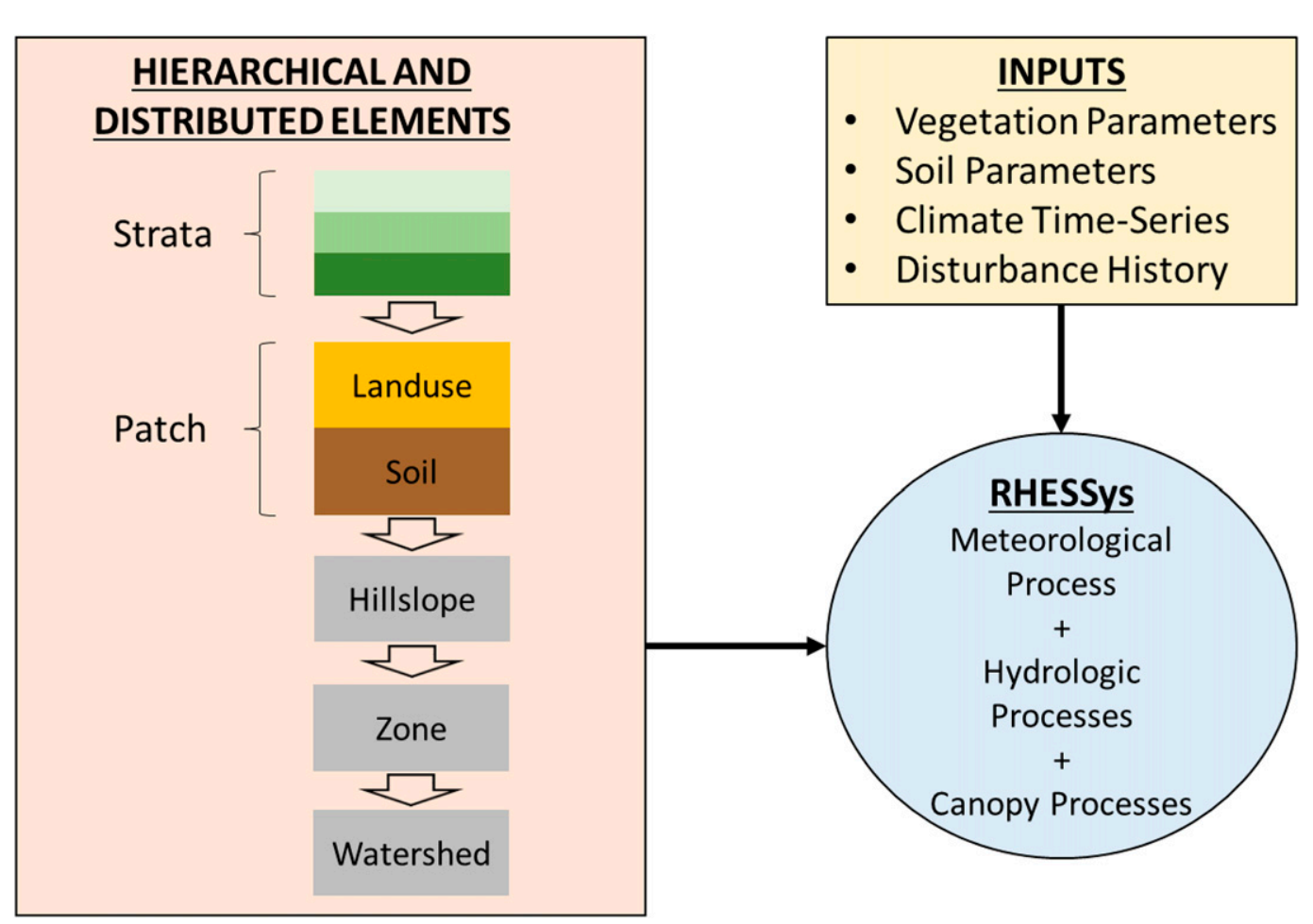

Figure 1. Schematic representation of the RHESSys modeling system.

vertical layers within a patch where processes like photosynthesis and transpiration are simulated.

The model operates primarily at a daily time step, although some aspects of hydrology, including overland flow routing, incorporate subdaily steps. Flow routing focuses on soil moisture redistribution. For smaller-scale simulations, routing uses an approach based on the Distributed Hydrology Soil Vegetation Model (DHSVM; Wigmosta et al. 1994), modified to account for nongrid-based patches and nonexponential transmissivity profiles. RHESSys does not represent channel routing; therefore, in-stream hydraulics and water quality kinetics are not simulated.

RHESSys was originally developed for forested systems but has been used successfully to simulate urban watersheds in both arid (e.g., Shields and Tague 2015) and humid climates (e.g., Mittman et al. 2012; Miles and Band 2015). Miles (2014) adapted the RHESSys code to simulate effects of GI on hydrology in small urban watersheds. We further expand those techniques, as described below.

\subsection{Study areas: Archetypal urban subunits (AUSs)}

RHESSys simulations in this study were designed as sensitivity analyses applied to a set of archetypal urban subunits (AUSs), representative of different urban settings and GI practices. Each AUS comprises an urban block and adjacent road 
Earth Interactions - Volume 22 (2018) • Paper No. 13 • Page 5

Table 1. AUS definition.

\begin{tabular}{lcl}
\hline Axis 1: Land use/imperviousness & Axis 2: Soils/infiltration capacity & \multicolumn{1}{c}{ Axis 3: BMP focus } \\
\hline Single family (24\% impervious) & High infiltration and depth & None \\
Multifamily (50\% impervious) & Medium infiltration and depth & Grassed swales and infiltration \\
$\begin{array}{l}\text { Commercial and retail } \\
\text { (80\% impervious) }\end{array}$ & Low infiltration and depth & Green roofs \\
\hline
\end{tabular}

area (represented as $10710 \mathrm{~m}^{2}$, or approximately one city block), draining to a single pour point. AUSs are defined according to three primary urban drainage characteristics (referred to as "axes") that interact with GI: land use/imperviousness, soil properties, and BMP type (Table 1). There were 36 different AUSs from the different combinations of conditions across the three axes. Other site factors were held constant to control variability and focus on the effects of these three factors.

For land use/imperviousness (axis 1), we simulated three levels of development intensity. The land-cover grids designed for the AUSs are representative of a typical urban environment with appropriate areas for roads and parking (Figure 2). Impervious areas in these layouts consist of rooftop, parking, sidewalk, and roads, while pervious areas comprise managed lawns and unmanaged grasses.

We designed synthetic elevation grids to route runoff from rooftops, parking lots, and sidewalks via roads to the pour point (lower right of design). Pervious land covers were assigned elevations higher than roads but lower than rooftops.

Pervious areas are simulated as turf grass, which requires irrigation in more arid climates. We use the representation of Milesi et al. (2005), in which irrigation of turf grass uses a fixed rate of $0.3629 \mathrm{~cm} \mathrm{day}^{-1}$ (including precipitation) for the simulations in the arid western United States (climate stations CA045114, NM290234, and CO050843). A fertilizer application rate of $0.005 \mathrm{kgN} \mathrm{m}^{-2} \mathrm{yr}^{-1}$ was also simulated on urban lawns based on a review of application rates by Carey et al. (2012).

Soil properties (axis 2) important to GI performance include depth, texture, and infiltration capacity. Our experimental design considered three levels of soil properties; however, results comparing relative performance with and without GI were not very sensitive to soil properties, so we focus on typical urban soils in the main text.

Intersecting spatial coverages of soil texture for the continental United States (Miller and White 1998) and the U.S. Census urbanized areas (U.S. Census Bureau 2010) shows that silt loam is the most prevalent class for urban areas (30\% of total). Soils in an urban environment are often compacted, which can reduce soil infiltration rates by up to $90 \%-98 \%$ from uncompacted conditions (Pitt et al. 2002). Gregory et al. (2006) report reduction in infiltration rates by $70 \%$ to $99 \%$ for converted forest and pasture land uses in north-central Florida as a result of compaction from construction activities. For this study, we reduced saturated hydraulic conductivity by approximately $75 \%$ of default nonurban value in RHESSys; specifically, we present results for compacted silt loam with vertical saturated hydraulic conductivity $\left(K_{\text {sat } 0}\right)$ at the surface reduced from the RHESSys default of 0.622 to $0.1555 \mathrm{~m} \mathrm{day}^{-1}$. Representative soil depth in urban areas is based on intersecting the dataset of Liu et al. (2014) with the urbanized areas coverage, 


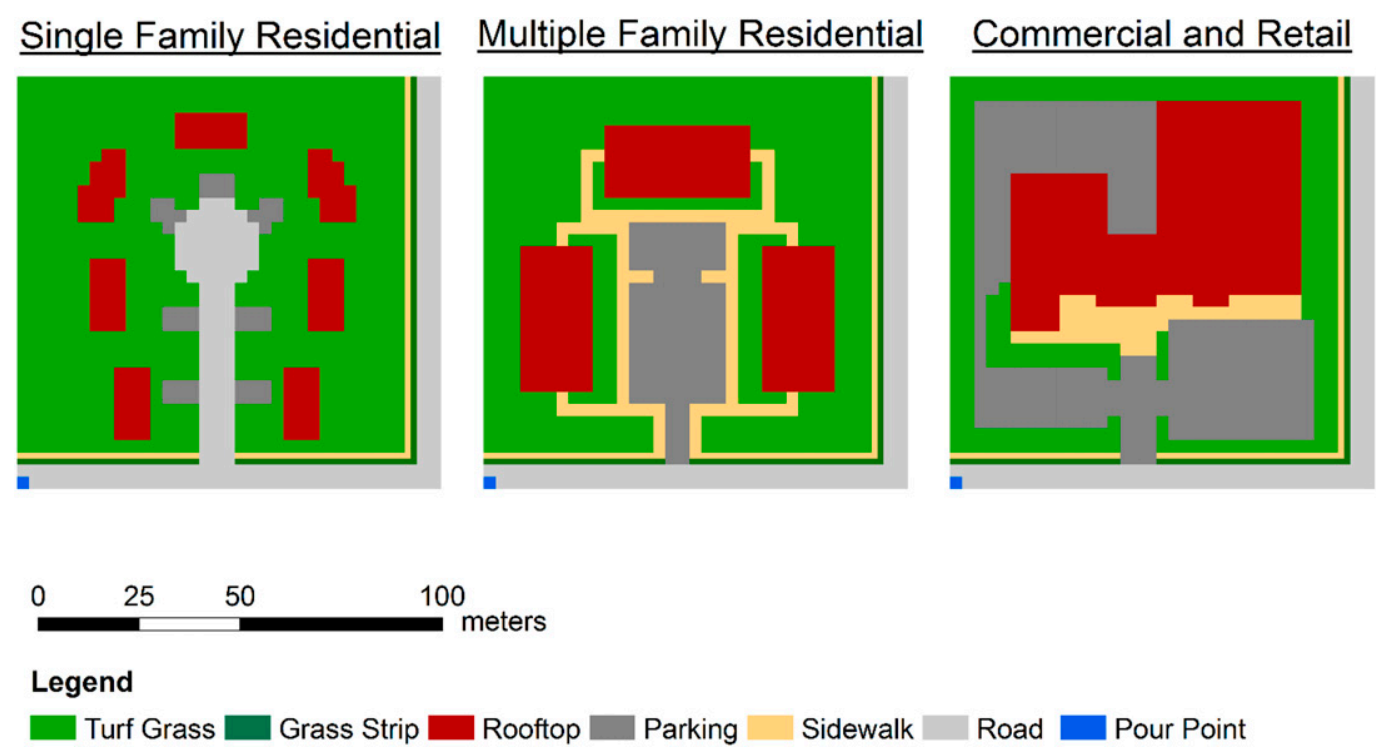

Figure 2. Land cover simulated for single-family residential, multifamily residential, and commercial/retail urban layouts.

yielding a mean ( \pm standard deviation) of approximately $1.5( \pm 0.45) \mathrm{m}$. In the real world, soil properties are likely to vary both within and between sites. Additional simulations assessing sensitivity to higher infiltration rates (up to $0.7775 \mathrm{~m} \mathrm{day}^{-1}$ ) and greater total soil depth (up to $3 \mathrm{~m}$ ), both of which may improve GI performance, are reported in the online supplemental material.

The third characteristic used to define AUSs is GI BMP type (axis 3). In these simulations, BMPs are not designed to provide a specific level of control; rather, different types of BMPs are evaluated separately to enable evaluation of the sensitivity of specific practices to climate change. (Real-world applications would likely combine a mix of BMPs, either in sequence or parallel, and may be designed to meet specific performance standards.) The BMP scenarios are intended to cover a range of common GI types, as follows:

1) No-GI: Simulation with no GI components provides a basis for comparison to designs with GI. Stormwater is handled with curb and gutter and subsurface piping. In most U.S. jurisdictions, stormwater from newer development is, at a minimum, routed through a detention basin for peak control, which alters the hydrograph and provides some trapping of sediment and sediment-associated pollutants, but minimal removal of dissolved constituents. Stormwater detention is not included in the AUS simulation because RHESSys does not simulate sediment transport or perform detailed hydraulic routing.

2) Swales and infiltration: Runoff from roofs, parking lots, and sidewalks is directed to grassed swales and areas that maximize potential infiltration. The design converts existing pervious areas to swales with remediated soils to promote infiltration. 
Earth Interactions - Volume 22 (2018) • Paper No. 13 • Page 7

Table 2. Area occupied by GI for land use/imperviousness type per $10710 \mathrm{~m}^{2}$ block.

\begin{tabular}{lccc}
\hline & \multicolumn{3}{c}{ Area covered $\left(\mathrm{m}^{2}\right)$} \\
\cline { 2 - 4 } \multicolumn{1}{c}{ Land use } & Swales and infiltration & Bioretention & Green roof \\
\hline Single family & 252 & 126 & 1134 \\
Multifamily & 486 & 324 & 1944 \\
Commercial and retail & 783 & 495 & 2808 \\
\hline
\end{tabular}

3) Bioretention: This scenario simulates bioretention incorporating deeprooted woody perennials. The design modifies natural flow paths to route all impervious surface runoff to dedicated bioretention areas. Bioretention includes an underdrain for native soils with low infiltration capacity.

4) Green roofs: Green roof designs have distinct characteristics and are not directly connected to native soils. They are most often used in denser plans with flat rooftops, but are also now designed for pitched roofs (up to about $35^{\circ}$ ). While green roofs are typically connected to other GI elements in a complete design, they are examined in isolation in this experiment to evaluate the characteristics of this specific BMP.

The spatial extent of swales/infiltration and bioretention are shown in the supplemental material (Figures S1, S2). Green roof is implemented on 100\% of the rooftops in the AUSs (shown in Figure 2). The area covered by GI component for each design is summarized in Table 2. The GI components have enhanced hydraulic conductivity relative to native soils achieved by soil amendments. For the low-infiltration scenario, we assumed the GI media has $K_{\text {sat0 }}=0.3048 \mathrm{~m}$ day $^{-1}$, equivalent to the minimum infiltration capacity recommended for bioretention and water quality swale designs (e.g., VWRRC 2011; NRCS 2005). For GI media $K_{\text {sat0 }}$ was increased along with the values for native soils in the sensitivity runs reported in the supplemental material.

All RHESSys simulations were set up with the AUS boundary as the defined basin with a single, uniform hillslope. Each unique land-use component in the design was assigned a different zone number. Although there are no variations in climate across an AUS for a selected climate scenario and location, the zone partitioning facilitates the analysis of fluxes at the land-use level. Canopy strata associated with land-use patches vary depending upon the scenario. Modifications to the RHESSys code needed to simulate the BMP scenarios are discussed in the supplemental material.

RHESSys daily output files report storage and fluxes of water, nitrogen, and carbon, as well as upward and downward fluxes of longwave and shortwave radiation, but do not estimate air temperature or urban "canyon" effects on heat absorption and turbulent exchange. Urban streets flanked by buildings on either side, creating a canyonlike environment, are commonly referred to as urban canyons. The vertical radiation exchanges between the Earth's surface and atmosphere are combined with evapotranspiration (ET) output to approximate the net impact on local temperature balance. A simplified energy balance for a land patch can be written as (Hewlett 1982)

$$
R_{n}-H-G-S_{R}-p-L_{V} \mathrm{ET}=0,
$$

where $R_{n}$ is the net longwave and shortwave radiation exchange between the land surface and atmosphere, $H$ is the sensible heat exchange between the surface and 
Earth Interactions - Volume 22 (2018) - Paper No. 13 • Page 8

Table 3. Weather stations for simulation with 1981-2000 climate norms. The Denton, TX, record is combined with additional information from nearby Dallas Love Field to obtain a full set of meteorological input variables.

\begin{tabular}{lllrrr}
\hline \multicolumn{1}{c}{ City } & Station & \multicolumn{1}{c}{ Name } & $\begin{array}{c}\text { Elevation } \\
(\mathrm{m})\end{array}$ & $\begin{array}{c}\text { Mean } \\
\text { temperature } \\
\left({ }^{\circ} \mathrm{C}\right)\end{array}$ & $\begin{array}{c}\text { Annual } \\
\text { precipitation } \\
(\mathrm{cm})\end{array}$ \\
\hline New Orleans, LA & LA166660 & New Orleans AP & 4 & 29.9 & 159 \\
Atlanta, GA & GA090451 & Atlanta Hartsfield & 308 & 17.0 & 126 \\
Worcester, MA & MA199923 & Worcester AP & 305 & 8.8 & 122 \\
Tampa, FL & FL088788 & Tampa WSCMO AP & 6 & 22.3 & 105 \\
Cleveland, OH & OH331657 & Cleveland AP & 235 & 10.8 & 99 \\
Dallas, TX & TX412404 & Denton, TX & 192 & 17.9 & 97 \\
Portland, OR & OR356751 & Portland AP & 6 & 12.5 & 92 \\
Minneapolis, MN & MN215435 & Minneapolis St. Paul AP & 266 & 7.9 & 78 \\
Boulder, CO & CO05843 & Boulder 2 & 1672 & 10.9 & 53 \\
Los Angeles, CA & CA045114 & Los Angeles Intl AP & 30 & 17.0 & 33 \\
Albuquerque, NM & NM290234 & Albuquerque AP & 1618 & 14.0 & 24 \\
\hline
\end{tabular}

atmosphere, $G$ is the conduction of heat through the land surface, $S_{R}$ is the change in heat storage in the watershed, $p$ is the chemical energy conversions in photosynthesis and respiration, $L_{V}$ is the latent heat of vaporization of water $(2.48 \times$ $10^{6} \mathrm{~J} \mathrm{~kg}^{-1}$ at $10^{\circ} \mathrm{C}$ ), and ET is the mass of water evaporated. For long-term averages (30-yr time frame in this study), $S_{R}, G$, and $p$ can be assumed to be negligible. The sensible heat exchange, which accounts for local warming of the air, can then be approximated as

$$
H=R_{n}-L_{V} \times \mathrm{ET} .
$$

Most GI installations will have only a small effect on $R_{n}$, but can have a large effect on ET, and thus on $H$. The ratio $\left(L_{V} \times \mathrm{ET}\right) / R_{n}$ represents the fraction of incoming radiation that is mitigated by ET.

\section{Historic and future climate scenarios}

RHESSys simulations were completed for 11 climate zones representative of different U.S. cities. Simulations were first completed using historic climate, and performances were compared against published literature. Simulations were then completed using future climate to assess the impacts on GI performance. The representative sites were selected to leverage climate scenario data available from a previous modeling study (U.S. EPA 2013; Johnson et al. 2015) and represent a range of elevation, temperature, and precipitation found within the contiguous United States (Table 3).

Historic climate data at each location were acquired from nearby NCDC primary airport stations for a 30-yr historic baseline period (approximately 1971-2000, with some variation between sites depending on data availability). Wet and dry atmospheric deposition of reduced and oxidized nitrogen was included for each location based on the 2000-13 average of total deposition grids provided by the 
Earth Interactions - Volume 22 (2018) • Paper No. 13 • Page 9

Table 4. NARCCAP GCM/RCM model combinations used to develop climate change scenarios. See appendix for GCM/RCM details.

\begin{tabular}{llll}
\hline Scenario & GCM & \multicolumn{1}{c}{ RCM } & Shorthand key \\
\hline 1 & CGCM3 & CRCM & CRCM_cgcm3 \\
2 & HadCM3 & HRM3 & HRM3_hadcm3 \\
3 & GFDL & RCM3 & RCM3_gfdl \\
4 & GFDL & GFDL hi res & GFDL_slice \\
5 & CGCM3 & RCM3 & RCM3_cgcm3 \\
6 & CCSM & WRFG & WRFG_ccsm \\
\hline
\end{tabular}

Total Deposition Program (TDEP; Schwede and Lear 2014). Nitrogen deposition rates are held constant under future climate scenarios.

Future climate scenarios for each of the 11 stations are based on climate model output for the period 2041-70 (midcentury) archived by the North American Regional Climate Change Assessment Program (NARCCAP). NARCCAP scenarios are developed by driving a number of different regional climate models (RCMs) on a 50-km grid with results from four global climate models (Table 4) from phase 3 of the Coupled Model Intercomparison Project (CMIP3) (Mearns et al. 2009, 2013). All scenarios assume the relatively high, Special Report on Emissions Scenarios (SRES) A2 greenhouse gas emissions trajectory (Nakicenovic et al. 2000). Differences among these emissions scenarios, however, are not substantial for the future time period considered here. The NARCCAP scenarios were interpolated to specific station locations, and historic time series for precipitation and temperature at each station were modified using a change factor approach that accounts for precipitation intensification to create the future time series [see Johnson et al. (2015) for details]. The range of future precipitation and air temperature for each location is shown in Figure 3. Evaporation and transpiration are

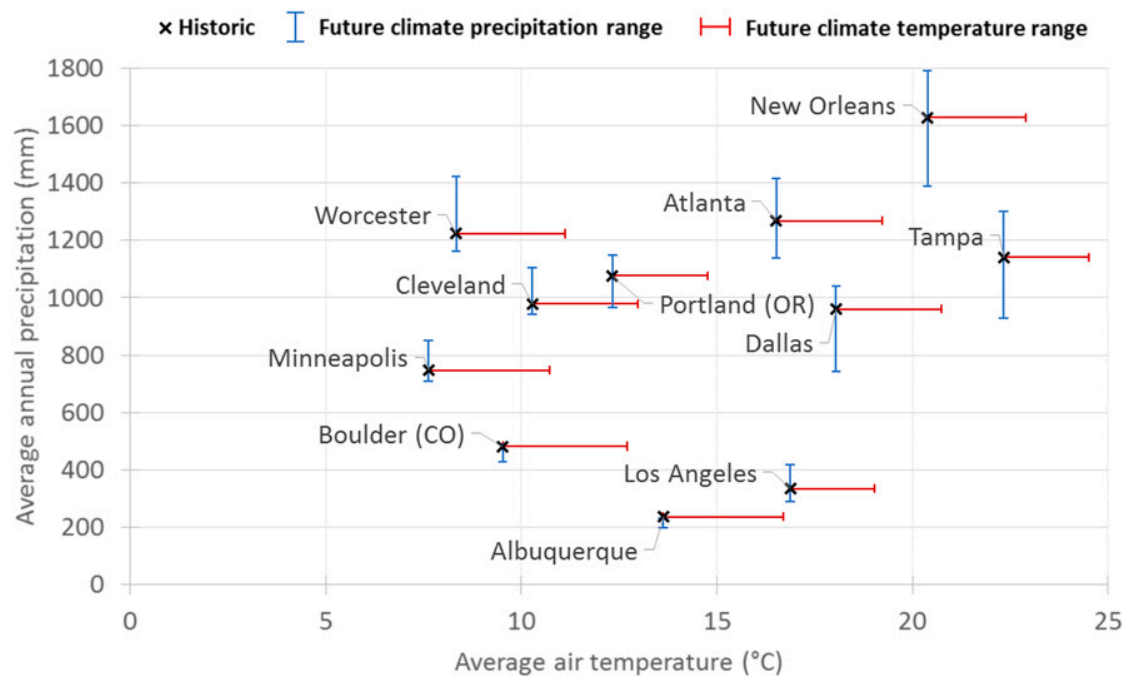

Figure 3. Historic annual average precipitation, average air temperature, and range of future precipitation and air temperature at each of the $11 \mathrm{cli}-$ mate locations. 
Earth Interactions - Volume 22 (2018) • Paper No. 13 • Page 10

computed by RHESSys internally using the Penman-Monteith approach (Monteith 1965), an energy balance method that accounts for the effects of future changes in the relationship between energy inputs. Climate models provide projections of future climate assessed with 30-yr averages of metrics and are not expected to predict future weather of any particular year or decade. GI response variables are, therefore, reported as annual averages over the entire simulation time period of 30 years.

All future climate scenarios assume a midcentury (2055) atmospheric carbon dioxide $\left(\mathrm{CO}_{2}\right)$ concentration of 527 ppmv, while historic climate runs assume a concentration of 369 ppmv. Atmospheric $\mathrm{CO}_{2}$ affects plant growth and leaf stomatal conductance, with effects on water loss through ET. Stomatal conductance is related to atmospheric $\mathrm{CO}_{2}$ concentration using Easterling et al.'s (1992) method with an adjustment factor of 0.4 in RHESSys. The equation was developed from crop systems in the Missouri-Kansas region and implies a $40 \%$ decrease in stomatal conductance in response to a doubling in atmospheric $\mathrm{CO}_{2}$ concentration. Jha et al. (2006) acknowledge that the literature suggests a lower rate of decrease is likely more appropriate for some plants and especially certain trees. The review of Medlyn et al. (2001) reported changes in mean stomatal conductance in forest species ranging from $-1 \%$ to $-24 \%$ in response to a doubling of atmospheric $\mathrm{CO}_{2}$ concentration. Uncertainties in stomatal conductance likely have considerable impacts on simulated ET under future climate.

\section{Results and discussion}

\subsection{Model testing}

A formal calibration and validation, comparing RHESSys simulations with empirical observations, was not possible because the simulations are conducted for hypothetical urban archetypes. Informal model testing was implemented, however, to ensure that the hydrology and water quality response of these synthetic watersheds are comparable to peer-reviewed studies in actual urban environments.

\subsubsection{Hydrology}

Runoff and ET are two major components of the water balance. ET is often the largest outflow component in natural systems, but in an urban environment, the hydrologic cycle is often altered by the presence of impervious surfaces. Impervious areas inhibit infiltration and ET while increasing runoff (Arnold and Gibbons 1996).

As a check on RHESSys urban hydrology, simulated runoff was compared to independent estimates, calculated using the simpler TR-55 curve number method (USDA 1986). We calculated runoff for each AUS under historic climate using a curve number of 98 for impervious surfaces and 84 for pervious areas representing open spaces.

Figure 4 shows the average annual return flow simulated by RHESSys for the commercial, multifamily, and single-family urban archetypes against runoff calculated using the TR-55 method. The return flow simulated by RHESSys is in close agreement with runoff calculated using the curve number method. 
Earth Interactions - Volume 22 (2018) • Paper No. 13 • Page 11

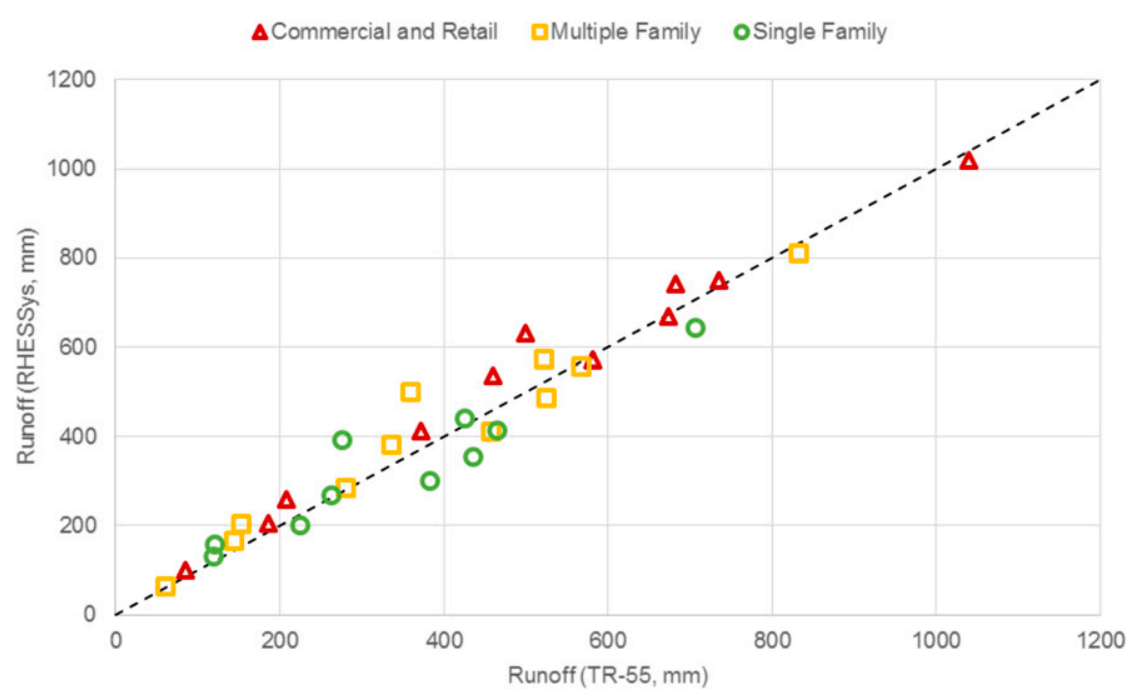

Figure 4. Simulated average annual return flow vs runoff calculated using TR-55 method.

Direct measurements of ET are generally lacking for urban areas. A water balance study conducted by Bhaskar and Welty (2012) for the Baltimore metropolitan area concludes that ET is approximately $31 \%$ of the precipitation for urban watersheds, compared to $73 \%$ for rural watersheds. Dow and DeWalle (2000), studying 51 watersheds in the eastern United States, concluded that ET decreases with an increase in urbanization. Their empirical relationship suggests a decrease in ET by $12 \mathrm{~cm} \mathrm{yr}^{-1}$ (around 17\%) for a watershed going from $0 \%$ to $50 \%$ urban land use. Figure 5 shows the average annual ET simulated by RHESSys for historic climate for the three urban layouts. Less ET occurs from the commercial layout, as it has the highest fraction of impervious area. The ratio of ET to precipitation varies between $20 \%$ and $50 \%$ [bracketing the $31 \%$ in Bhaskar and Welty (2012)], with the exception of the arid and semiarid regions where the ET is higher. The precipitation in these areas is augmented with irrigation, which leads to an increase in ET. The highest ET is simulated for the single-family AUS for the Boulder location.

\subsubsection{Carbon and nitrogen cycles}

Several studies have been conducted in recent years on biogeochemical processes in urban environments. Pouyat et al. (2006) have estimated the soil organic carbon pools (1-m depth) for six U.S. cities (Atlanta, Baltimore, Boston, Chicago, Oakland, and Syracuse). The estimated average soil carbon areal density for urban land within these cities ranges from 5500 to $7800 \mathrm{~g} \mathrm{~m}^{-2}$; the range across individual land uses is much larger, varying between 3300 and $14400 \mathrm{~g} \mathrm{~m}^{-2}$.

The Baltimore Ecosystem Study (BES; BES 2011) analyzed physical, chemical, and biological properties of home lawn soils for nine low-density and 23 medium/ high density residential plots. Interquartile ranges (IQRs) (25th-75th) for soil 


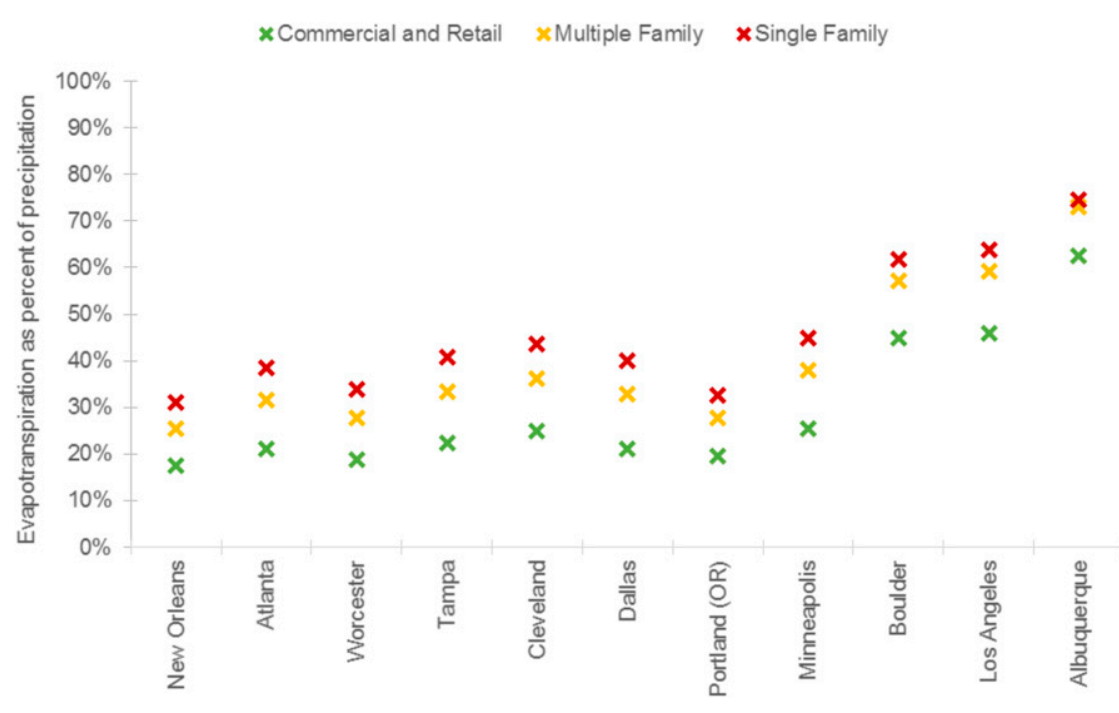

Figure 5. Ratio of simulated ET to precipitation for the urban archetypes. Boulder, Los Angeles, and Albuquerque simulations include lawn irrigation at a rate of $1000 \mathrm{~mm} \mathrm{yr}^{-1}$. Results are representative of individual climate stations in or near the named cities (see Table 3).

carbon and nitrogen were 961-1948 and 88-154 $\mathrm{g} \mathrm{m}^{-2}$, respectively, for the top $1 \mathrm{~m}$ of soil (Figure 6).

RHESSys-simulated 25 th and 75 th percentiles for soil carbon (over $1.5-\mathrm{m}$ depth) range between 2080 and $4429 \mathrm{~g} \mathrm{~m}^{-2}$ (Figure 6) and are generally lower than the

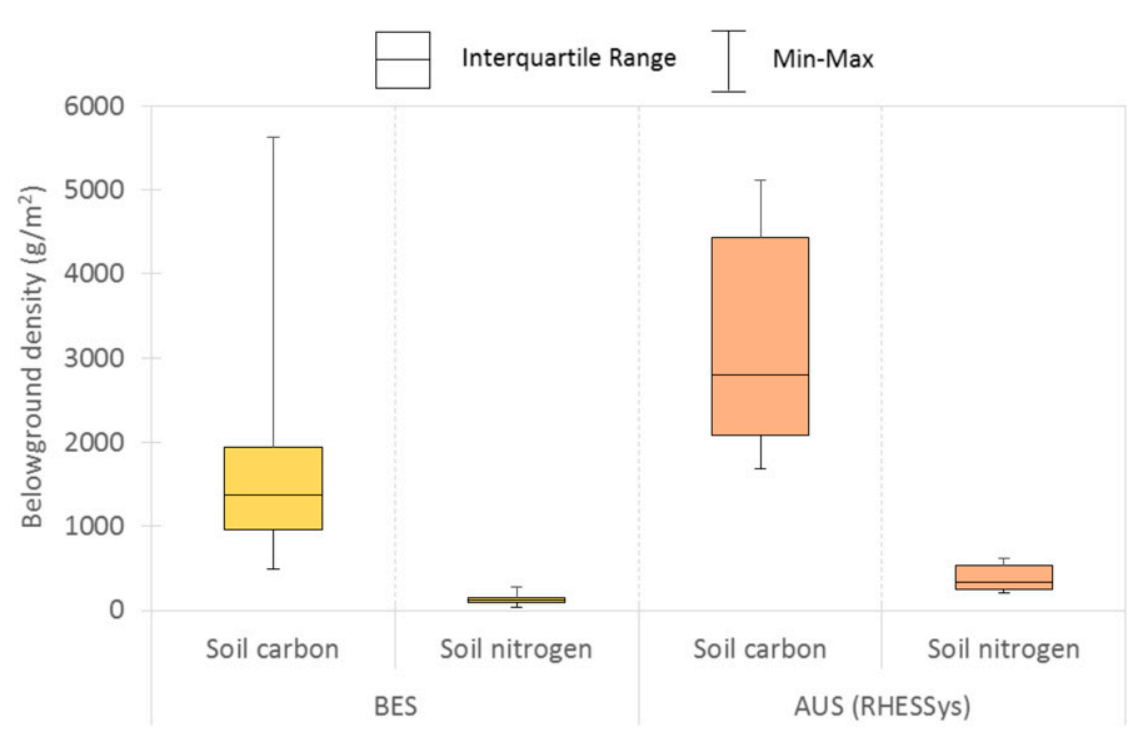

Figure 6. Comparison of RHESSys-simulated average soil carbon and nitrogen areal density to BES (2011) values for urban lawns across 32 residential plots. 
Earth Interactions - Volume 22 (2018) • Paper No. 13 • Page 13

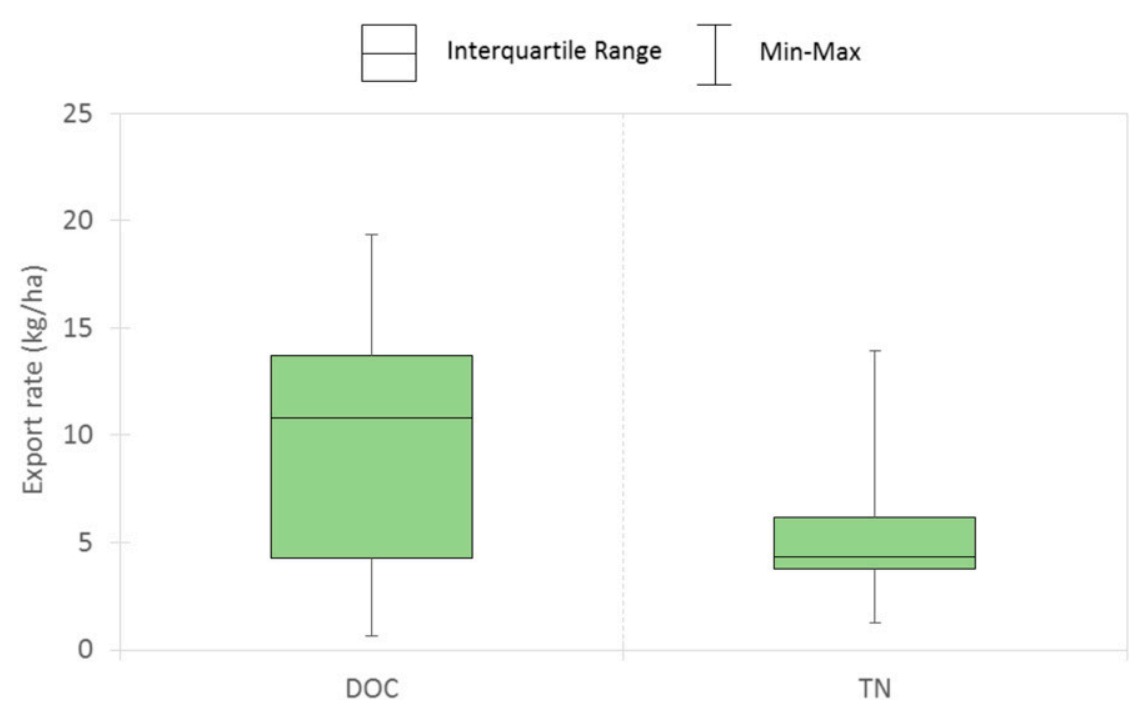

Figure 7. RHESSys-simulated average annual DOC and TN export rates across the AUSs.

estimates of Pouyat et al. (2006) but higher than BES (2011). There is likely to be significant site-specific variability associated with soil type, site history, and plant species.

The RHESSys-simulated soil nitrogen areal densities had an interquartile range of 250.5-534.1 $\mathrm{g} \mathrm{m}^{-2}$ (Figure 6). These are higher than reported by BES (2011), but integrate over 1.5-m instead of 1-m depth. Soil nitrogen is affected by fertilization practices, and lawn areas in the model have a simulated nitrogen application rate of $50 \mathrm{kgNha}^{-1}$. It may be that typical nitrogen fertilization practices in the BES are lower than those assumed in the RHESSys modeling.

Fluxes of nitrogen and carbon from urban watersheds have been reported by several recent studies. Smith and Kaushal (2015) report dissolved organic carbon (DOC) export rates of 8 to $40 \mathrm{kgC} \mathrm{ha}^{-1} \mathrm{yr}^{-1}$ for the Baltimore-Washington D.C. area. The range reported for total dissolved nitrogen (TDN) was 2.8 to $9.0 \mathrm{kgNha}^{-1} \mathrm{yr}^{-1}$. Sickman et al. (2007) attribute $10.5 \mathrm{kgC} \mathrm{ha}^{-1} \mathrm{yr}^{-1}$ to nonpoint urban sources in the Sacramento River. Groffman et al. (2004) report nitrogen yields ranging from 2.9 to $7.9 \mathrm{kgN} \mathrm{ha}^{-1} \mathrm{yr}^{-1}$ for six urban/suburban watersheds in the Baltimore metropolitan area. Figure 7 shows average annual DOC and total nitrogen (TN) export rates simulated by RHESSys. The simulated DOC outflow varies between 0.8 and $20.1 \mathrm{~kg} \mathrm{ha}^{-1} \mathrm{yr}^{-1}$. TN yield varies between 1.5 and $12.3 \mathrm{~kg} \mathrm{ha}^{-1} \mathrm{yr}^{-1}$. For a given location, DOC yield is generally highest from the single-family design and lowest from the commercial design. A similar trend is observed with TN yield. The comparison suggests RHESSys simulations for $\mathrm{C}$ and $\mathrm{N}$ in this study are reasonable.

Yang (2013) notes that stream-dissolved organic carbon export in RHESSys is influenced by three key soil parameters: the rate at which concentration of dissolved organic matter (DOM) decays with depth, the DOM production rate, and the DOC absorption rate. The second and third of these parameters were left at default values, while the first was raised to $1.0 \mathrm{~kg} \mathrm{~m}^{-1}$ in this study to approximate the reported rate of DOC export in urban streams. 
Earth Interactions - Volume 22 (2018) • Paper No. 13 • Page 14

Although the study design lacks a formal calibration and validation exercise, the comparisons of the model predictions to literature suggest the RHESSys simulations provide a reasonable basis for evaluating climate sensitivity.

\subsection{GI performance under current climate}

\subsubsection{Hydrology}

Simulation results confirm that implementation of GI reduces direct surface runoff (Figure 8) and increases base flow (Figure 9) under historic climatic conditions relative to no GI. Total water yield decreases with the implementation of GI, while ET increases. Simulated runoff was most sensitive to impervious density and BMP type but exhibited little sensitivity to soil properties (see supplemental material). The reduction in median runoff with GI (relative to No-GI) varies between $18 \%$ and $29 \%$ as impervious coverage is increased from $24 \%$ (single family) to $80 \%$ (commercial and retail). The reductions by BMP type were $12 \%, 23 \%$, and $33 \%$ for swales/infiltration, bioretention, and green roof, respectively.

Median baseflow increase for GI varied between 5\% and 37\% as impervious density changed from $24 \%$ (single family) to $80 \%$ (commercial and retail). Sensitivity to soil infiltration and depth was low, with an average increase in median base flow of approximately $16 \%$ (range of $15.7 \%$ to $17.3 \%$ ). The increase in median GI base flow relative to No-GI was lowest for green roof (10\%) and highest for bioretention $(24.4 \%)$. Increase for swales and infiltration was $13 \%$ relative to No-GI.

The climate regime has the potential to impact GI performance, so we further analyze GI behavior across 11 locations representative of different climates. We report the results as percent change under GI calculated relative to No-GI for the same location/impervious density/soil combination. The simulated range of change in runoff and base flow is shown in Figures 10 and 11. Runoff generally decreases, while base flow increases with GI. A reduction in total flow volume occurs due to an increase in ET for the arid locations (Boulder, Los Angeles, and Albuquerque). The higher impervious density designs generally exhibit large relative changes, as higher imperviousness generates more runoff volumes; therefore, a larger magnitude of runoff is treated by GI for higher impervious density AUSs. The changes in volumes generally show little variation among the different locations, although small differences are expected on account of different climates.

Decreases in total flow volume relative to No-GI are simulated at all locations for bioretention. The reduction in total flow is generally on account of an increase in ET. Since bioretention is designed to store water, a significant proportion of the runoff entering bioretention leaves the system as ET. Runoff volumes decrease, while base flow increases. ET generally increases, with the exception of the arid locations, where a decrease is simulated (like swales and infiltration). Like swales and infiltration, larger changes are simulated for urban layouts with higher impervious density. The relative changes in volumes vary across the selected locations due to differences in climate and biogeochemical processes that influence GI behavior.

The reductions in surface runoff reported here are smaller than those shown in the Driscoll et al. (2015) summary of GI BMP performance. Based on the average of storm events at individual sites, they reported mean volume reductions in storm 

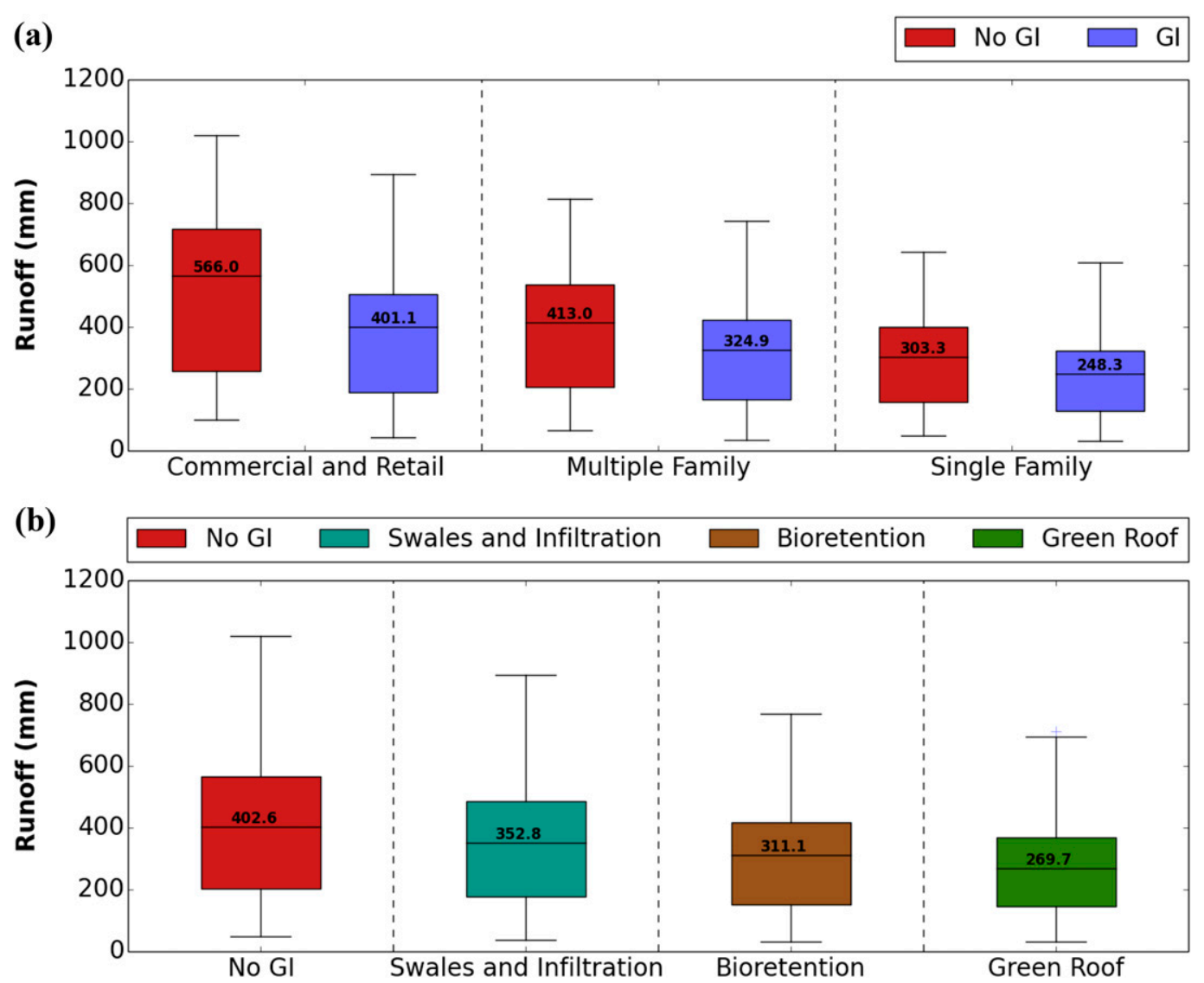

Figure 8. Simulated runoff under historic climate summarized by (a) land use and impervious density and (b) BMP type. In these figures, the box represents the IQR, while the whiskers represent the range Q1-1.5 IQR and $Q 3+1.5$ $I Q R$, where $Q 1$ and $Q 3$ are the first and third quartiles, respectively. In (a), the box plots show variation in annual average AUS runoff response across 11 climate regions and three land-use and impervious density conditions. In (b), the box plots show variation in annual average AUS runoff response across 11 climate regions, three soil infiltration and depth conditions, and three land-use and impervious density conditions by GI type. The + signs in some plots show outliers or points that fall outside the range represented by the whiskers.

flow of $26 \%, 65 \%$, and $52 \%$ for swales, bioretention, and green roofs, respectively. However, the results of Driscoll et al. (2015) are for the BMP inflow and outflow alone, not for a whole AUS, and thus are expected to be larger.

\subsubsection{Nitrogen}

Compared to No-GI, use of GI causes median TN yield to decrease (Figure 12). Decreases relative to No-GI were not very sensitive to impervious density or soil infiltration and depth. TN yield was, however, somewhat sensitive to BMP type. 

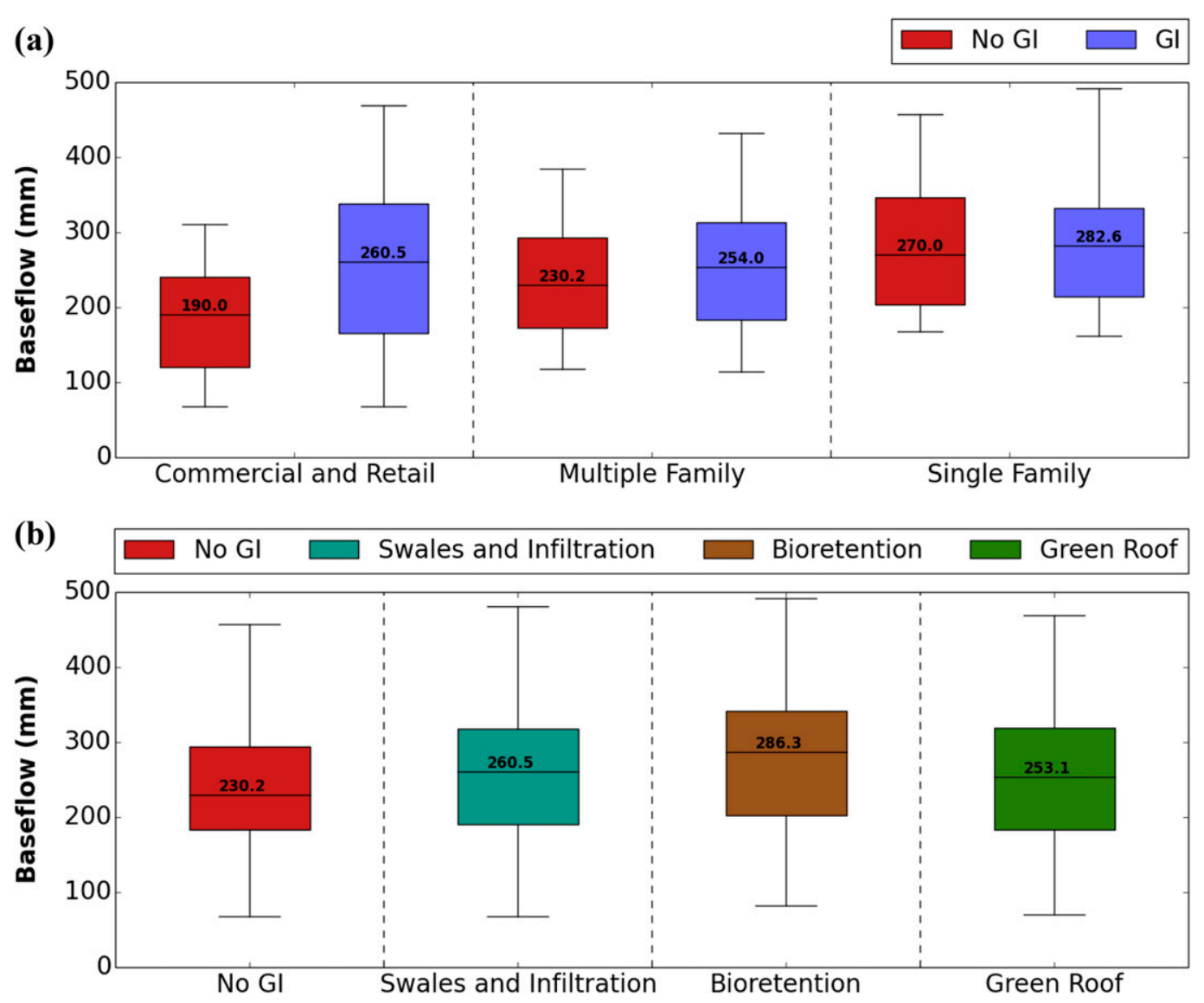

Figure 9. As in Figure 8, but for simulated base flow under historic climate summarized by (a) land use and impervious density, and (b) BMP type.

Modest decreases of $3 \%$ and $9 \%$ in TN yield relative to No-GI were simulated for swales and infiltration and bioretention, respectively. A slight increase in TN yield was simulated for green roof.

We further analyze TN yield under GI relative to No-GI across impervious density and GI combinations for the locations selected for this study (Figure 13). Swales and infiltration and bioretention generally show a decrease in TN yield relative to No-GI. The reduction is greatest for the commercial and retail design and least for the single-family design. The variation in yield decreases across the selected are generally minor and are likely explained by the differences in climate. Annual reductions at the block scale tend to be less than those reported by Driscoll et al. (2015) at the storm event and BMP scale (average 4\% and 57\%, respectively, for swales and bioretention).

The results for green roof are less consistent. While some location and impervious density combinations show a net decrease, others simulate a net increase relative to No-GI. Green roofs in the model are fertilized at a rate of $2.7 \mathrm{~kg} \mathrm{ha}^{-1}$ to sustain plant growth. The increases are likely explained by a combination of fertilization and a net import of nitrogen to the system (associated with green roof 
Earth Interactions - Volume 22 (2018) • Paper No. 13 • Page 17

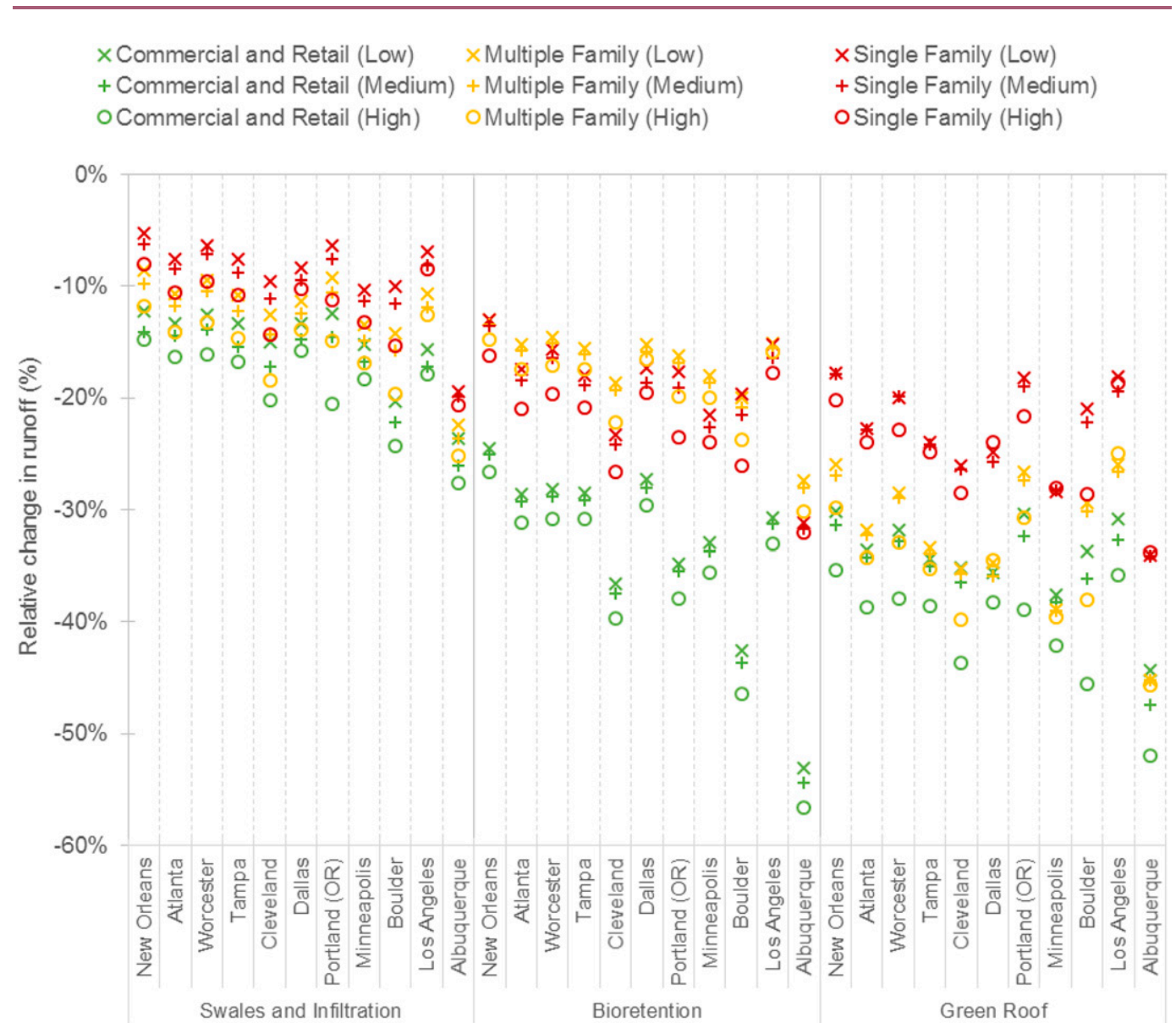

Figure 10. Simulated changes in runoff volumes for $\mathrm{GI}$ under different impervious densities and soil infiltration and depth (low, medium, and high) for 11 locations under historic climate. The figure shows change in annual average GI runoff volume relative to No-GI for all impervious density/soil combinations at each of the 11 representative locations.

media and plant). We also simulated green roofs with no fertilization of media, but the model still simulated a net increase in TN yield due to the creation of additional rooftop pervious area with imported media and plants. Relative increases are greatest for the drier climates (Los Angeles and Albuquerque) because of a large increase in simulated net nitrification (nitrification - denitrification). Decrease in net nitrification under certain climates explains the decreases in TN yield simulated for some location and impervious density combinations.

\subsubsection{Carbon}

Compared to No-GI, median DOC yield generally increases (Figure 14). Increases relative to No-GI were sensitive to impervious density, soil infiltration and depth, and BMP type. The largest increase in DOC yield by BMP type was 
Earth Interactions - Volume 22 (2018) - Paper No. 13 • Page 18

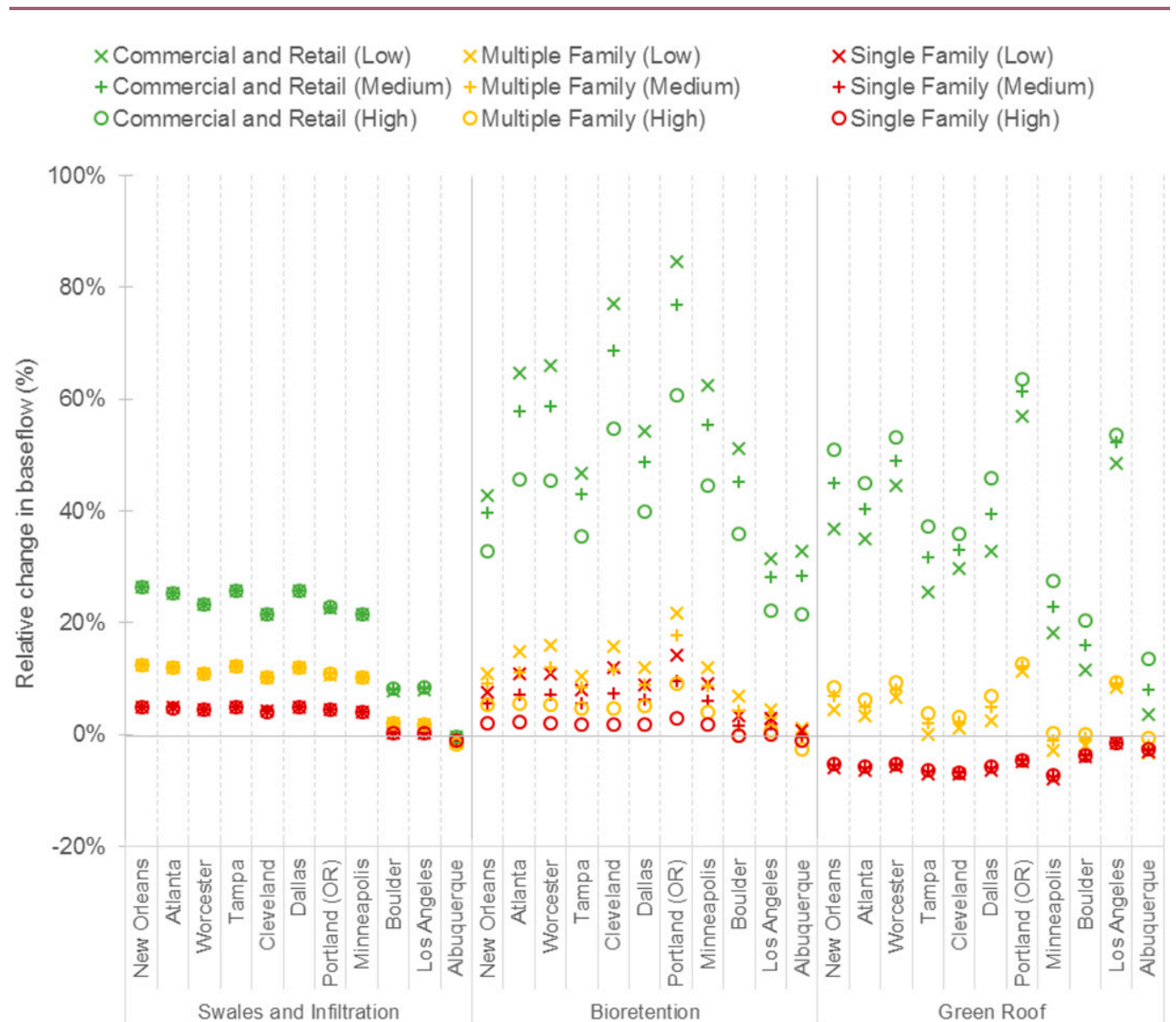

Figure 11. As in Figure 10, but for simulated changes in baseflow volumes.

simulated for green roof relative to No-GI, while a net decrease (although small) was simulated for bioretention.

We further analyze DOC yield under GI relative to No-GI across impervious density and GI combinations for the locations selected for this study (Figure 15). The results are less conclusive for swales and infiltration and bioretention, with some location/impervious density combinations showing a net increase and others showing a net decrease relative to No-GI. The simulated variations are due to differences in biogeochemical processes in different climates. DOC yields are predicted to increase for green roof for all location/impervious density combinations relative to No-GI due to the substitution of imported media and plants for inert roof areas. On average, the total system carbon (soil + plant + litter carbon) increases 59\% across the selected locations for green roof, relative to No-GI for the commercial and retail design, with a range of $36 \%-88 \%$. The increase in total system carbon is lower for the multifamily and single-family designs because these designs have smaller roof area than the commercial and retail design. 

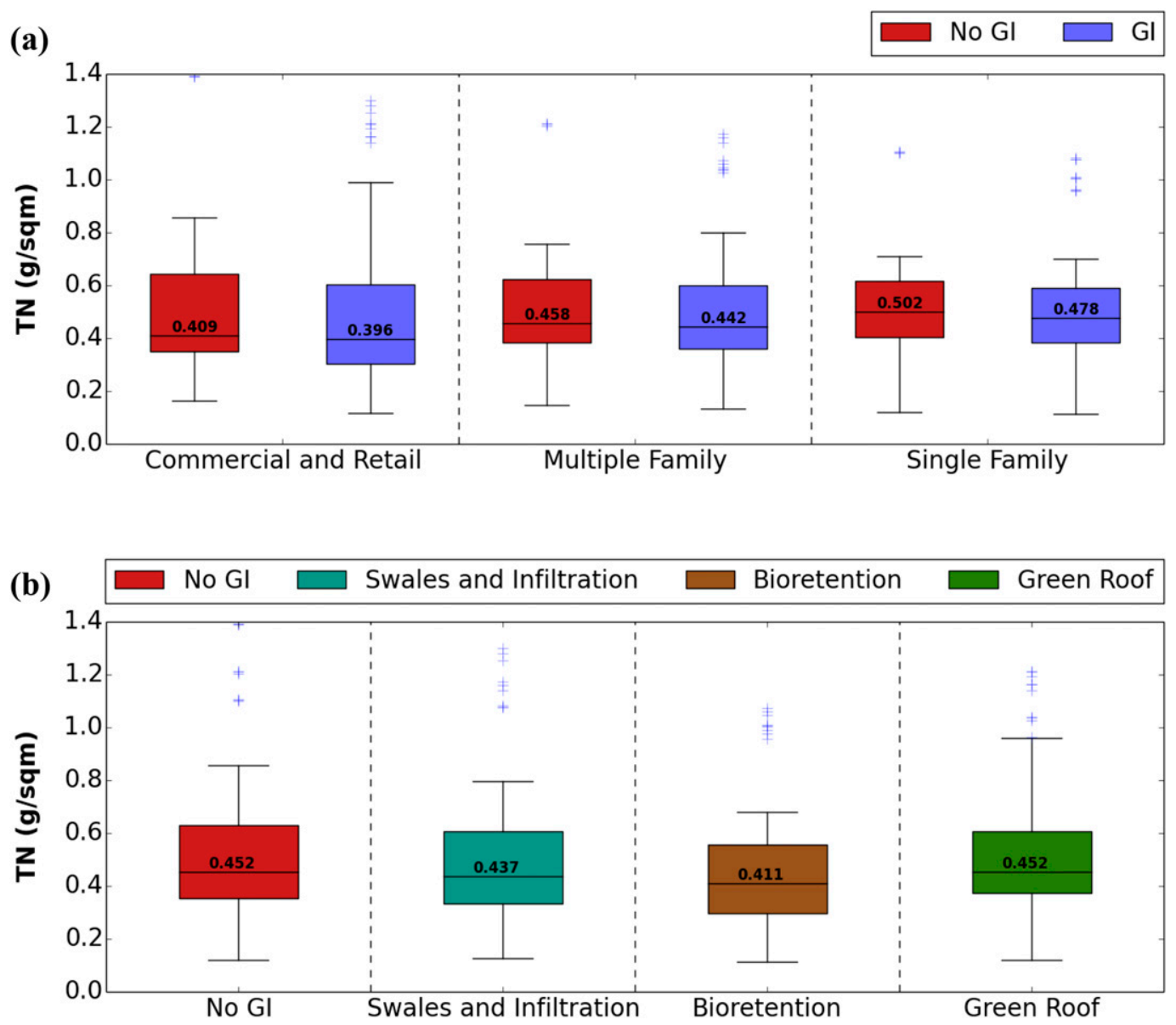

Figure 12. As in Figure 8, but for simulated TN load under historic climate summarized by (a) land use and impervious density, and (b) BMP type.

\subsection{GI performance with climate change}

Sensitivity of flow, TN, and DOC for GI (and No-GI) scenarios under future climate are first evaluated against impervious density, soil infiltration and depth, and BMP type (Figures 16-19). The trends suggest that GI behavior relative to NoGI remains relatively similar under future climate, compared to historic climate. GI total flow ad runoff decreases relative to No-GI under future climate, while base flow and ET increase. Changes in GI flows relative to No-GI are most sensitive to impervious density and BMP type. Sensitivity to soil infiltration and depth is generally low. GI TN and DOC behavior under future climate is similar to that reported under historic climate.

In the subsequent sections, we present the results of 30-yr RHESSys simulations assessing future changes in stormwater hydrology, nitrogen, carbon, and energy outputs. We summarize GI (and No-GI) behavior under future climate as change relative to the No-GI scenario under historic climate, first by location and then by impervious density. For example, in Figure 20 (top), the data points used to 
Earth Interactions - Volume 22 (2018) - Paper No. 13 • Page 20

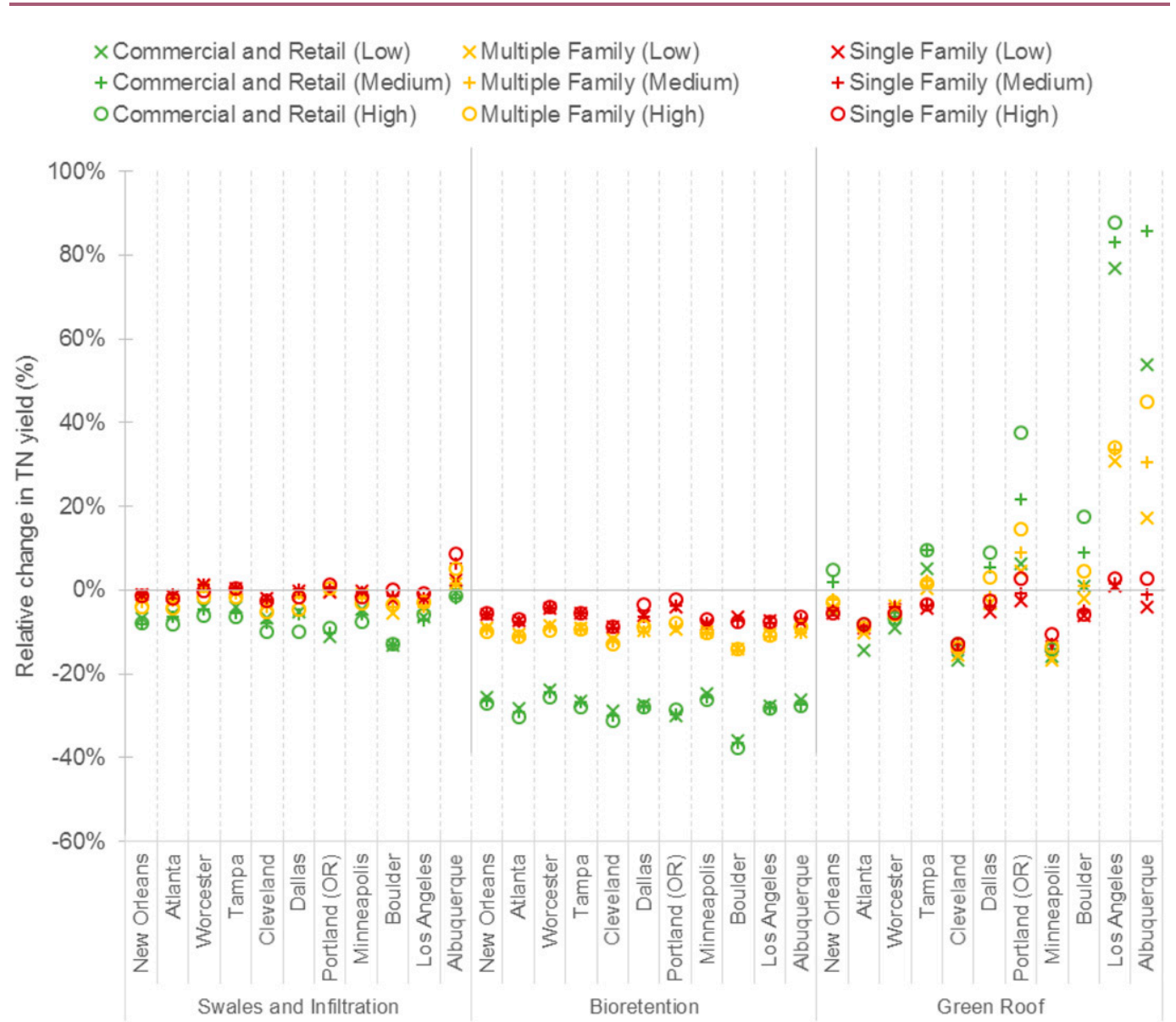

Figure 13. As in Figure 10, but for simulated changes in TN yield.

construct the box and whiskers for GI (and No-GI) at a given location consisted of determining the change in GI runoff volume at that location under future climate relative to No-GI runoff volume at the same location for all impervious density/soil combinations. Similarly, for Figure 20 (bottom), for a given impervious density, the change in runoff volume for a GI under historic climate is relative to No-GI under historic climate for every location/soil combination. Expressing results as relative changes is more robust than absolute values due to selective cancelling of consistent bias and error.

\subsubsection{No-GI}

AUS simulations driven by future climate change scenarios without BMPs show changes in runoff from $-30 \%$ to $+30 \%$, depending on the climate scenario and location (Figure 20). This suggests a potential risk of inadequate sizing of gray infrastructure, but does not show a consistent direction of change among scenarios. Runoff differences among climate change scenarios are largely due to differences in projected future precipitation among the climate change scenarios evaluated (see Table 4). 

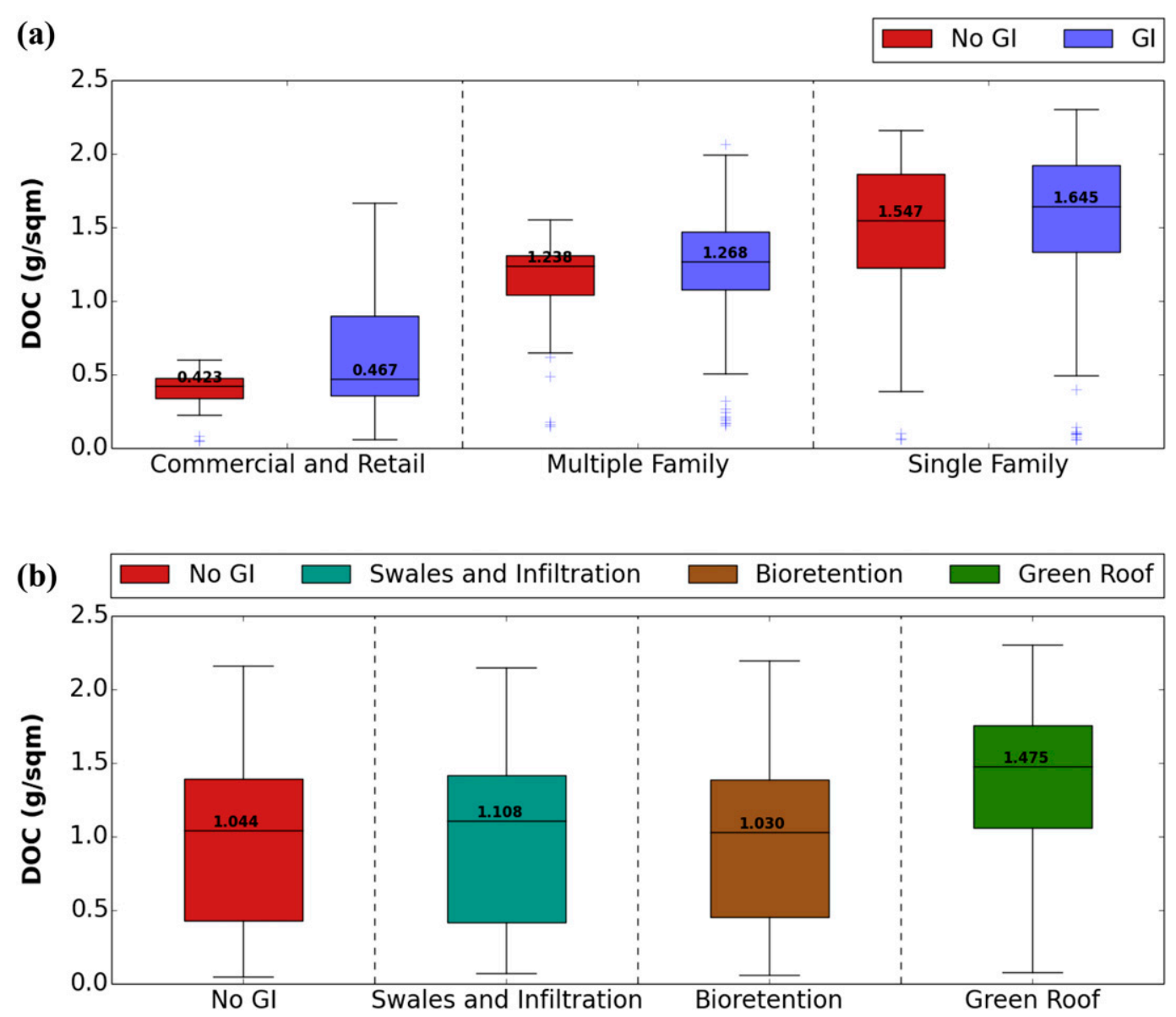

Figure 14. As in Figure 8, but for simulated DOC load under historic climate summarized by (a) land use and impervious density, and (b) BMP type.

\subsubsection{GI performance}

Figures 20 and 21 show simulated relative changes in runoff and base flow, respectively, by geographic location and impervious density for all GI BMPs under future climate relative to No-GI under historic climate. We use box-and-whisker plots, in which the box represents the IQR. The whiskers extend to the most extreme data points that are within \pm 1.5 times the IQR from the box, while individual outliers beyond this range are plotted. The figures show trends in GI BMP performance under altered climate conditions that are similar to those observed under historic climate. The No-GI scenario shows an increase in runoff for several climate scenarios. All GI scenarios under future climate show a net reduction in runoff relative to No-GI under historic conditions; however, in scenarios where total flow increases (e.g., HRM3_hadgem3 at Los Angeles), future runoff with GI may be substantially elevated relative to performance under historic climate. This suggests a potential need under certain conditions to reevaluate sizing criteria associated with achieving specific treatment goals. Nonetheless, in most cases, GI 
Earth Interactions - Volume 22 (2018) • Paper No. 13 • Page 22



Figure 15. As in Figure 12, but for simulated changes in DOC yield.

appears to be capable of offsetting the probable increase in runoff in these urban areas due to climate change through the middle of the twenty-first century. The largest reductions are observed for bioretention and green roof, and the relative change is largest for the commercial AUS because it has the greatest impervious fraction. Simulated decreases in return flow are typically accompanied by an increase in base flow, ET, or both.

Under most scenarios, GI is predicted to cause a net decrease in TN yield under future climate relative to No-GI under historic climate, with notable exceptions primarily associated with the Albuquerque site and for fertilized green roofs at the Los Angeles site (Figure 22).

Simulated changes in DOC yield are more variable than changes for nitrogen. Bioretention generally shows a decrease, but swales show a decrease at some locations and an increase at others (Figure 23). DOC export increases for green roofs due to net import of soil and plant biomass into the system. Note that we are simulating green roofs without other GI components; in most real designs, flow from the roof would be routed to bioretention or other GI that would help mitigate the load increases. 

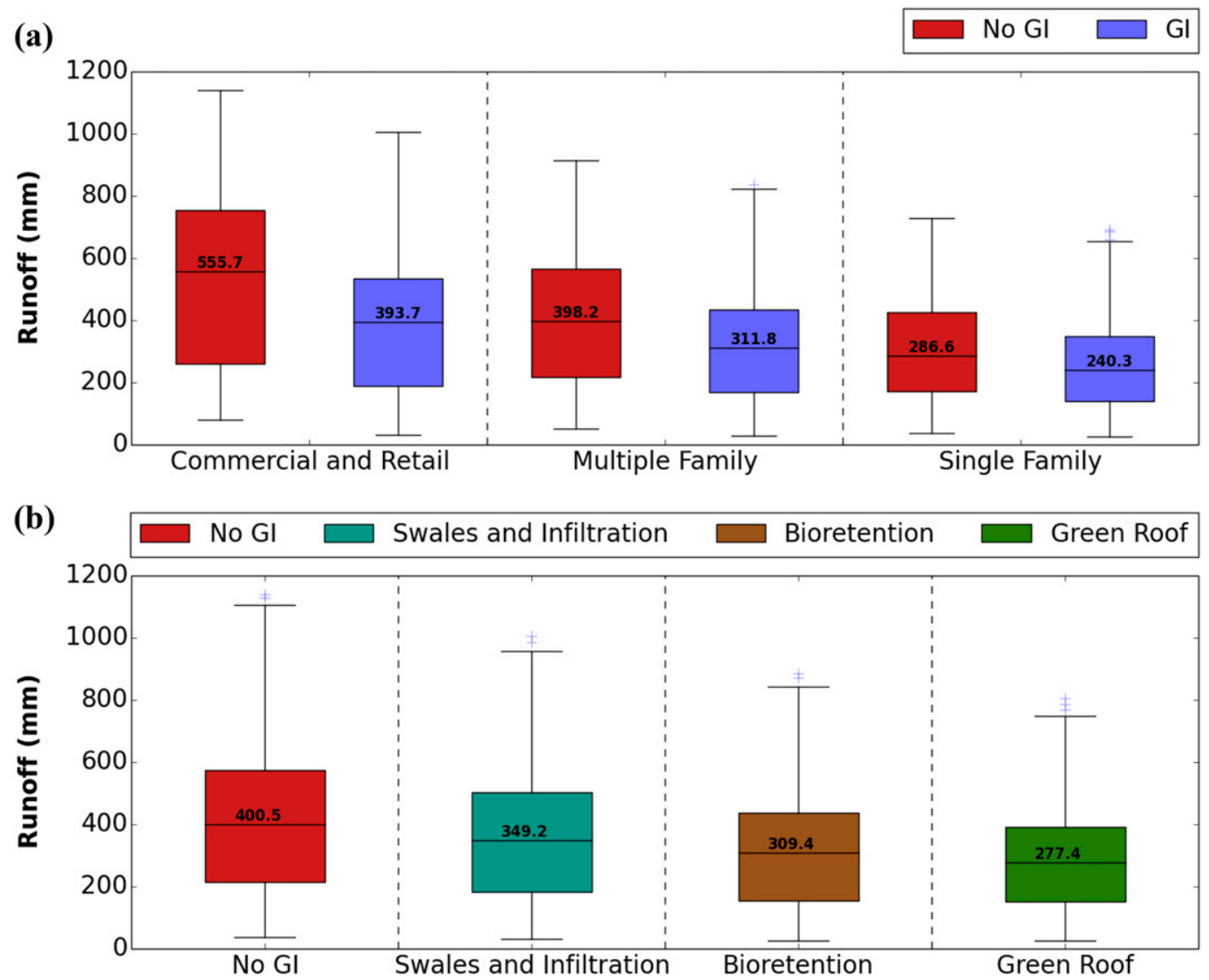

Figure 16. Simulated runoff under future climate summarized by (a) land use and impervious density and (b) BMP type.

Green roofs show the highest change in soil carbon primarily because of a net import of soil and plant biomass to the system. Soil carbon content generally decreases under future climate as soil temperatures rise, leading to higher decay rates. Swales and bioretention also show a small net increase in system soil carbon under historic climate, indicating the carbon sequestration potential of the practices. Under future climate, however, swales and bioretention show a net increase in soil carbon for some scenarios and a net decrease for others, depending on the soil moisture balance. Figure 24 summarizes changes in total flow, return flow, base flow, ET, DOC, and TN for GI under historic climate relative to No-GI under historic climate.

\subsection{Co-benefits of urban green infrastructure}

GI is implemented primarily to control urban runoff and associated pollutant loads; however, the plant and soil-based systems used in GI also affect a variety of biogeochemical processes of interest, including carbon storage, greenhouse gas emissions, and the local energy balance. These aspects of GI performance may also 



Figure 17. As in Figure 16, but for simulated base flow.

be sensitive to climate change. Here, we briefly summarize RHESSys predictions relative to these topics.

\subsubsection{Carbon storage and greenhouse gas emissions}

RHESSys provides a useful framework for assessing potential impacts on urban GHG balances due to its finescale representation of soils, soil moisture, and hydrology, which are controlling factors in hot spots and hot moments of GHG emissions (Groffman et al. 2009). RHESSys simulates carbon input to the system via photosynthesis and flux to the atmosphere as soil and plant respiration. The model does not directly simulate the production and net balance of GHGs such as $\mathrm{CO}_{2}, \mathrm{CH}_{4}$, and $\mathrm{N}_{2} \mathrm{O}$; however, important precursor reactions are represented. For $\mathrm{N}_{2} \mathrm{O}$ production, RHESSys simulations suggest that denitrification rates (average $1.92 \mathrm{gN} \mathrm{m}^{-2} \mathrm{yr}^{-1}$ under historic climate without GI BMPs) will increase, on average, about $17 \%$ under future climate scenarios, due primarily to increased soil temperature. The swales and bioretention GI components are predicted to reduce 

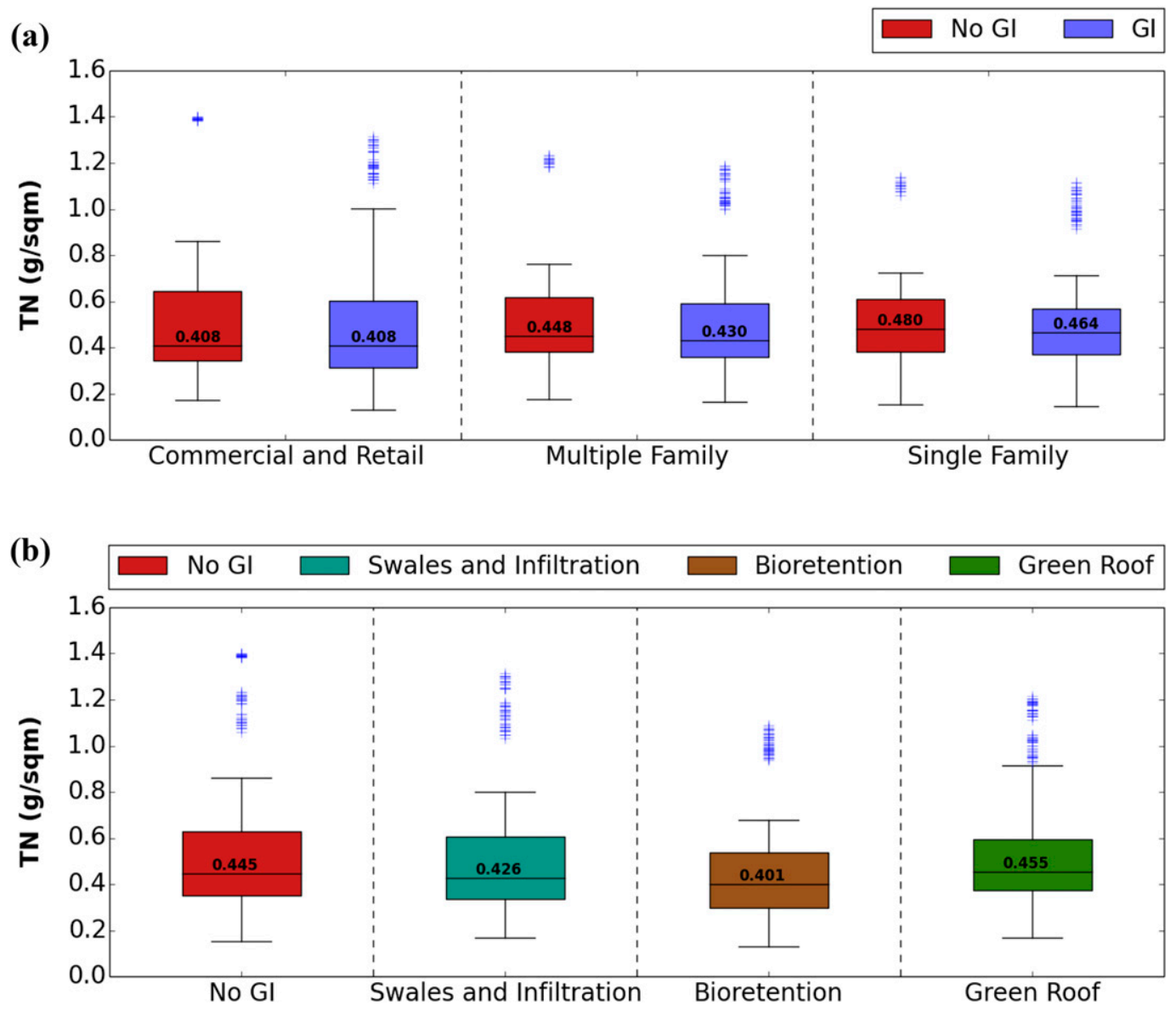

Figure 18. As in Figure 16, but for simulated TN load.

denitrification under historic climate and help mitigate increases under future climate (see Table S2 for details).

For carbon, the majority of respiration output will be as $\mathrm{CO}_{2}$ with $\mathrm{CH}_{4}$ emissions from saturated anoxic soils. These will mostly be emitted to the atmosphere, with a minor component of dissolved inorganic carbon export. While RHESSys does not distinguish $\mathrm{CO}_{2}$ and $\mathrm{CH}_{4}$ as state variables, the sum of photosynthetic uptake of atmospheric carbon less gross respiration from all pools and net storage of $\mathrm{C}$ is a useful index of the interaction of BMPs, climate change, and carbonaceous GHG balance. The RHESSys simulations for No-GI under historic conditions indicate a net export of $\mathrm{C}$ derived from soils and grass, largely as gas, and an average decline in the above-defined index under all six future climate scenarios. This suggests decreased carbon sequestration and greater GHG emissions in the future. The GI scenarios for swales and bioretention show greater net storage and lower emissions of $\mathrm{C}$, with net $\mathrm{C}$ sequestration under historic climate, but the swales and bioretention scenarios mitigate only about half of the climate-related changes. Green roofs are net sources of $\mathrm{C}$, with increasing losses under future climate (see Figure 25). Tabular 

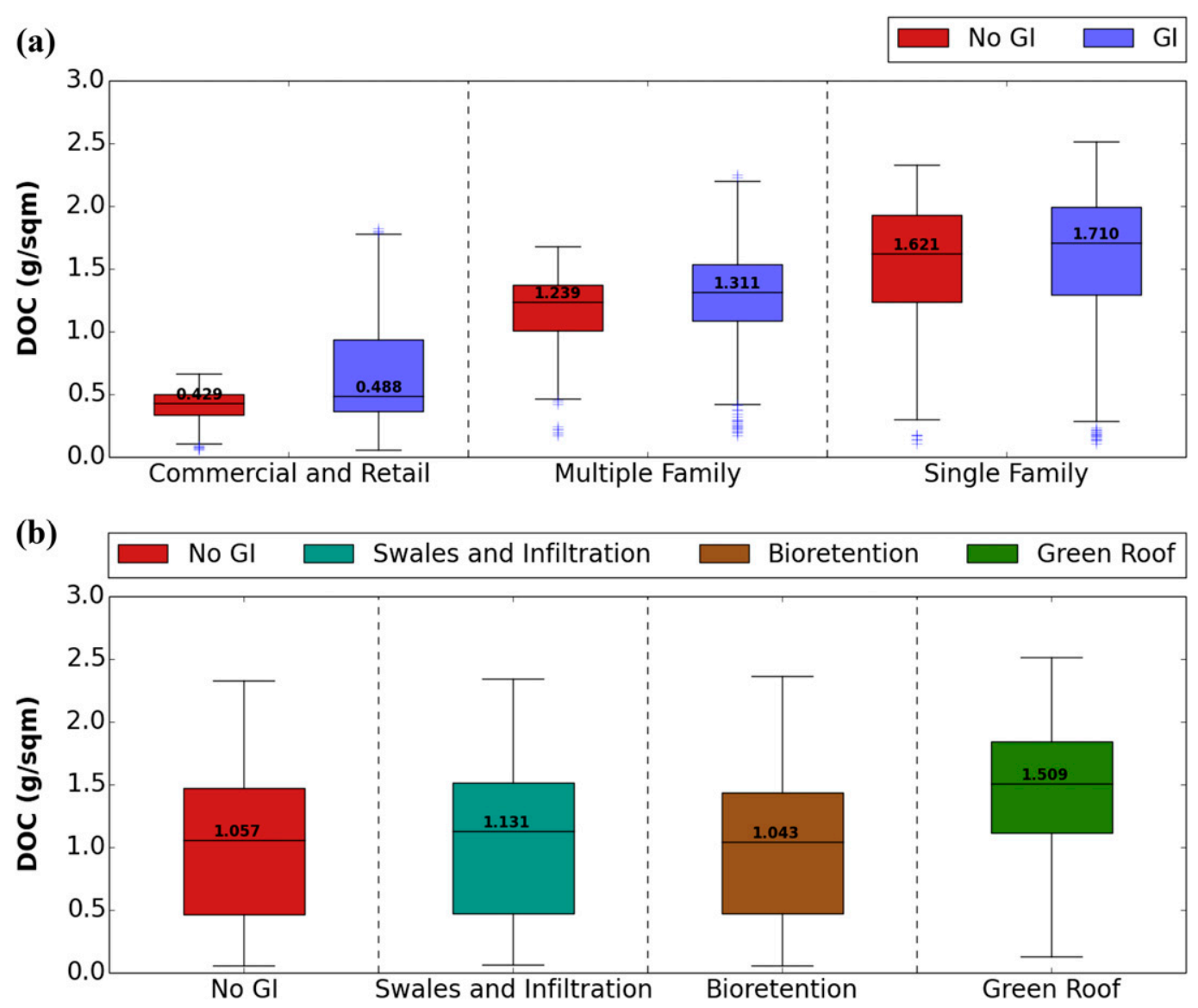

Figure 19. As in Figure 16, but for simulated DOC load.

summaries of the projected changes in denitrification and $\mathrm{C}$ balance are provided in the supplemental material.

Future enhancements to RHESSys to incorporate estimates of specific GHGsas have, for instance, been done in recent versions of the biogeochemical cycling models DAYCENT (e.g., Del Grosso et al. 2005, 2009) and DNDC (Li et al. 2000) - could provide a promising tool for quantitative evaluation of the interaction of urban GI and GHG net emissions.

\subsubsection{Energy balance and cooling}

Based on simulations using RHESSys, $4 \%$ to $8 \%$ of incoming radiation is converted to latent heat at the AUS or city block scale, resulting in local evaporative cooling. Swales and bioretention provide only small net gains in latent heat conversion over the whole AUS because their footprint is small; in contrast, green roofs can increase the fraction converted to ET at most sites (Figure 26), providing some mitigation for local atmospheric warming. At the driest sites (Boulder, Los Angeles, and Albuquerque), the model predicts that swales and bioretention result 


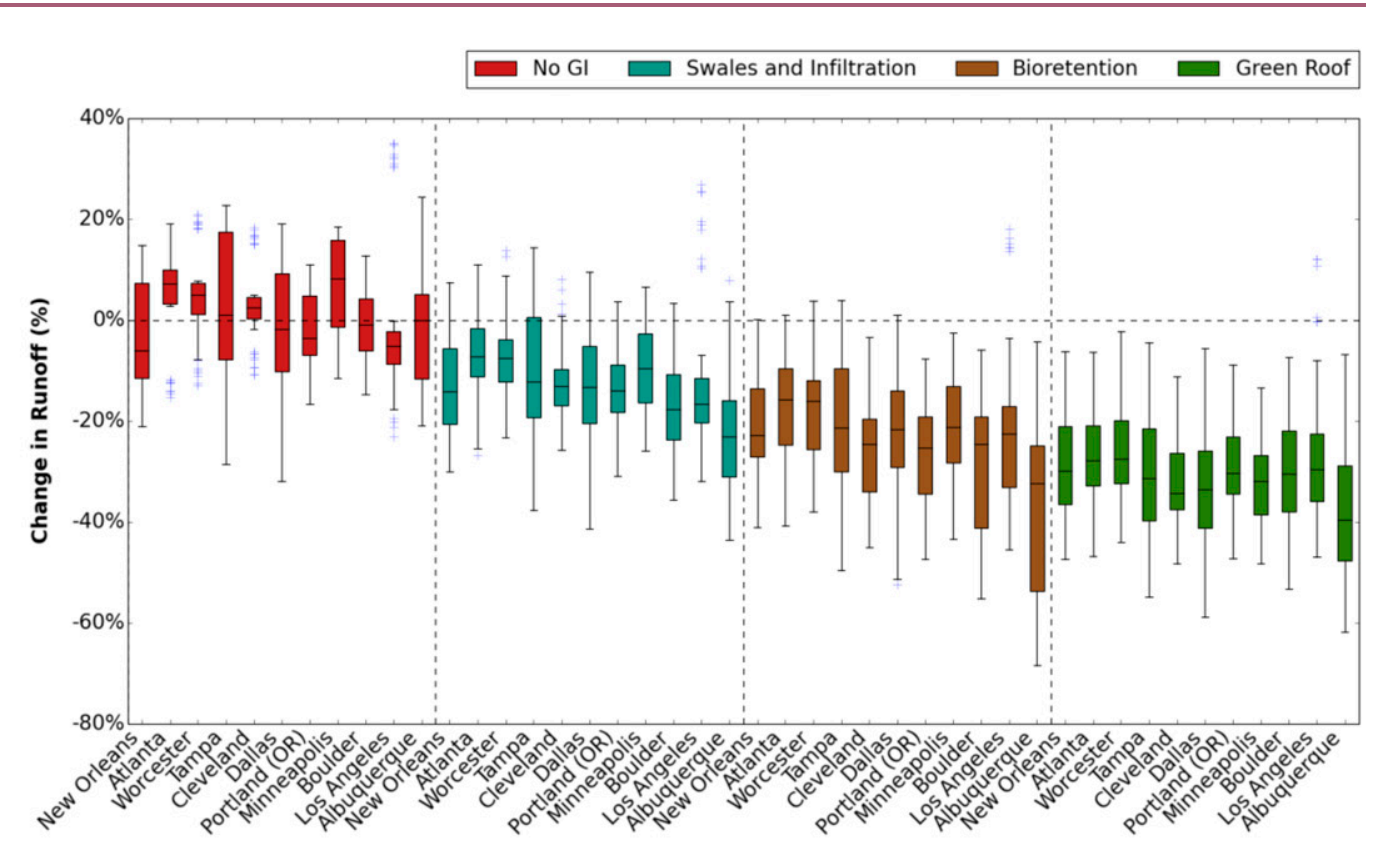

Location

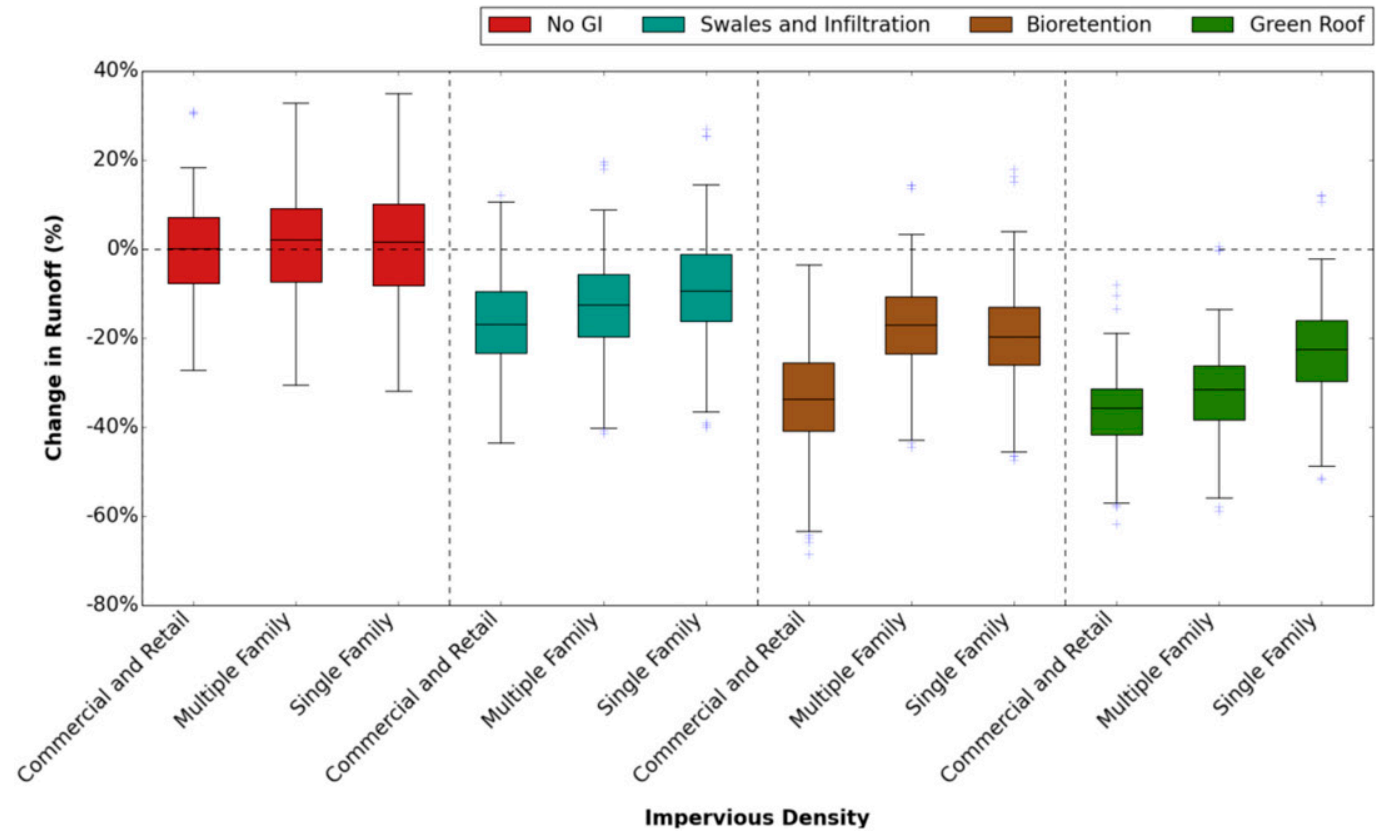

Figure 20. Simulated change in runoff volumes under future climate relative to historic climate for each GI type, separated by (top) location and (bottom) impervious density. The box represents the IQR, while the whiskers represent the range $Q 1-1.5$ IQR and $Q 3+1.5$ IQR, where $Q 1$ and $Q 3$ are the first and third quartiles, respectively. (top) The range of change in annual average $\mathrm{GI}$ runoff volume under future climate relative to No-GI under historic climate at each location for all impervious density/soil combinations. (bottom) The range of change in annual average $\mathrm{GI}$ runoff volume under future climate relative to No-GI under historic climate for each impervious density layout for all location/soil combinations. The plus signs (in some plots) show outliers or points that fall outside the range represented by the whiskers. 


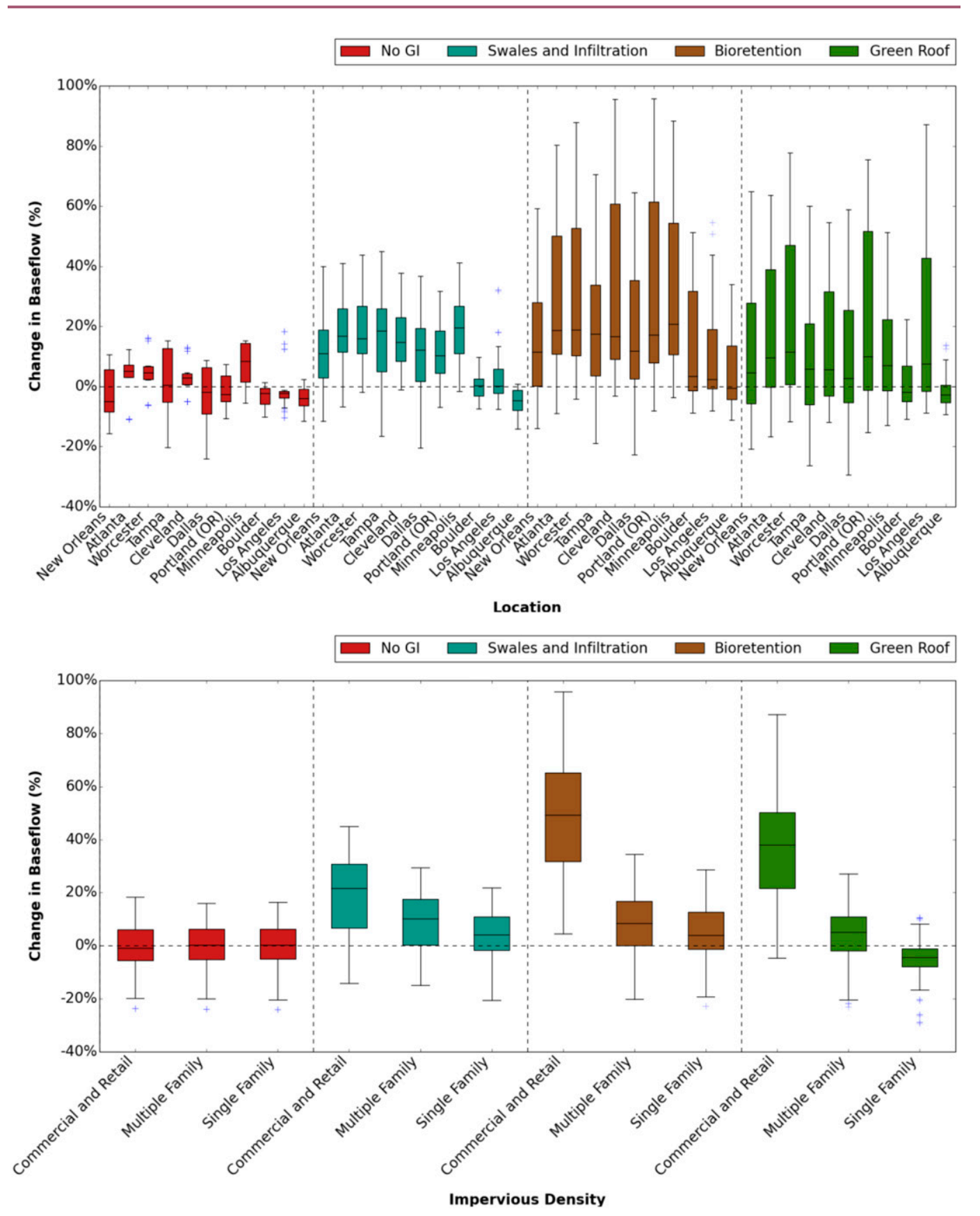

Figure 21. As in Figure 20, but for simulated change in baseflow volumes.

in a small net loss in conversion to latent heat, as precipitation that would normally evaporate instead percolates to groundwater. These results are consistent with the study of Georgescu et al. (2014) who suggest that cool roofs and green roofs in urban adaptation strategies have the potential to help mitigate the impacts of global warming on urban heat islands. 


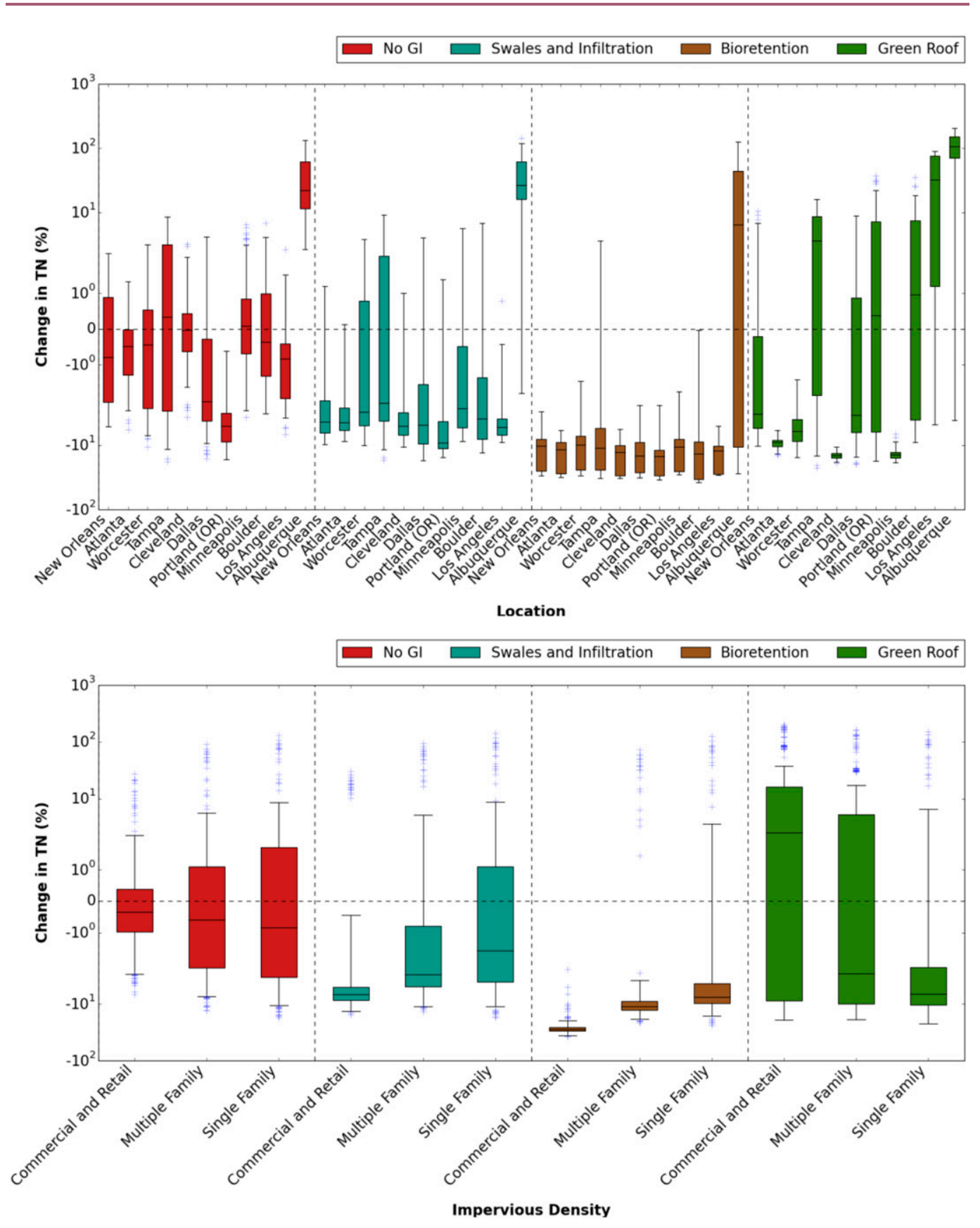

Figure 22. As in Figure 20, but for simulated change in TN yield.

\section{Conclusions}

Managing the risk of climate change impacts on stormwater requires an improved understanding of the effectiveness of different management responses for reducing impacts under a range of potential future climatic conditions. GI appears 


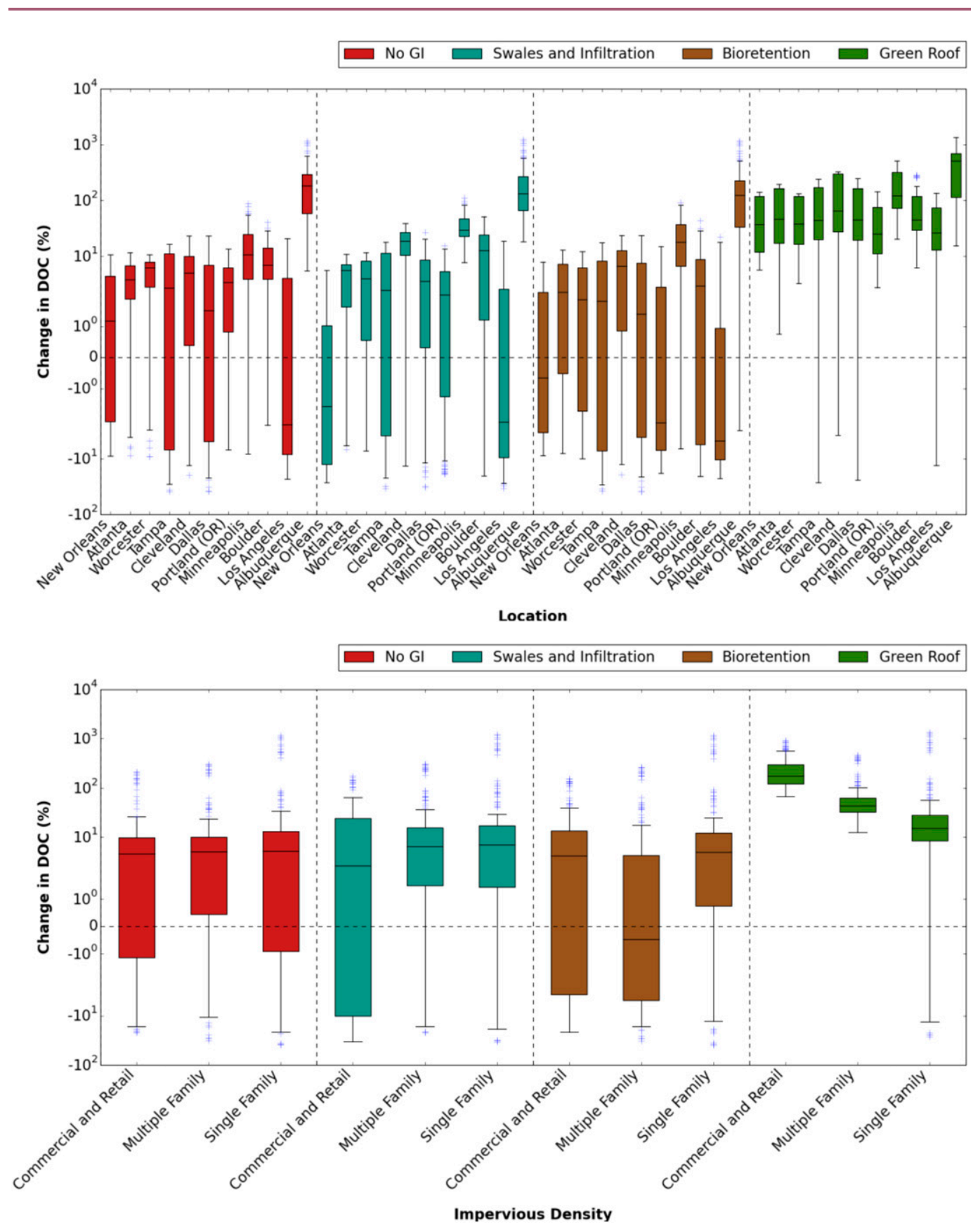

Figure 23. As in Figure 20, but for simulated change in DOC yield.

to provide advantages relative to engineered "hard" structures for managing stormwater due to greater flexibility and shorter design horizon, which could help facilitate adaptation to future climate as it occurs. GI can also provide co-benefits, such as mitigation of the urban heat island effect, which may be of particular value under a warming climate. 
Earth Interactions - Volume 22 (2018) • Paper No. 13 • Page 31

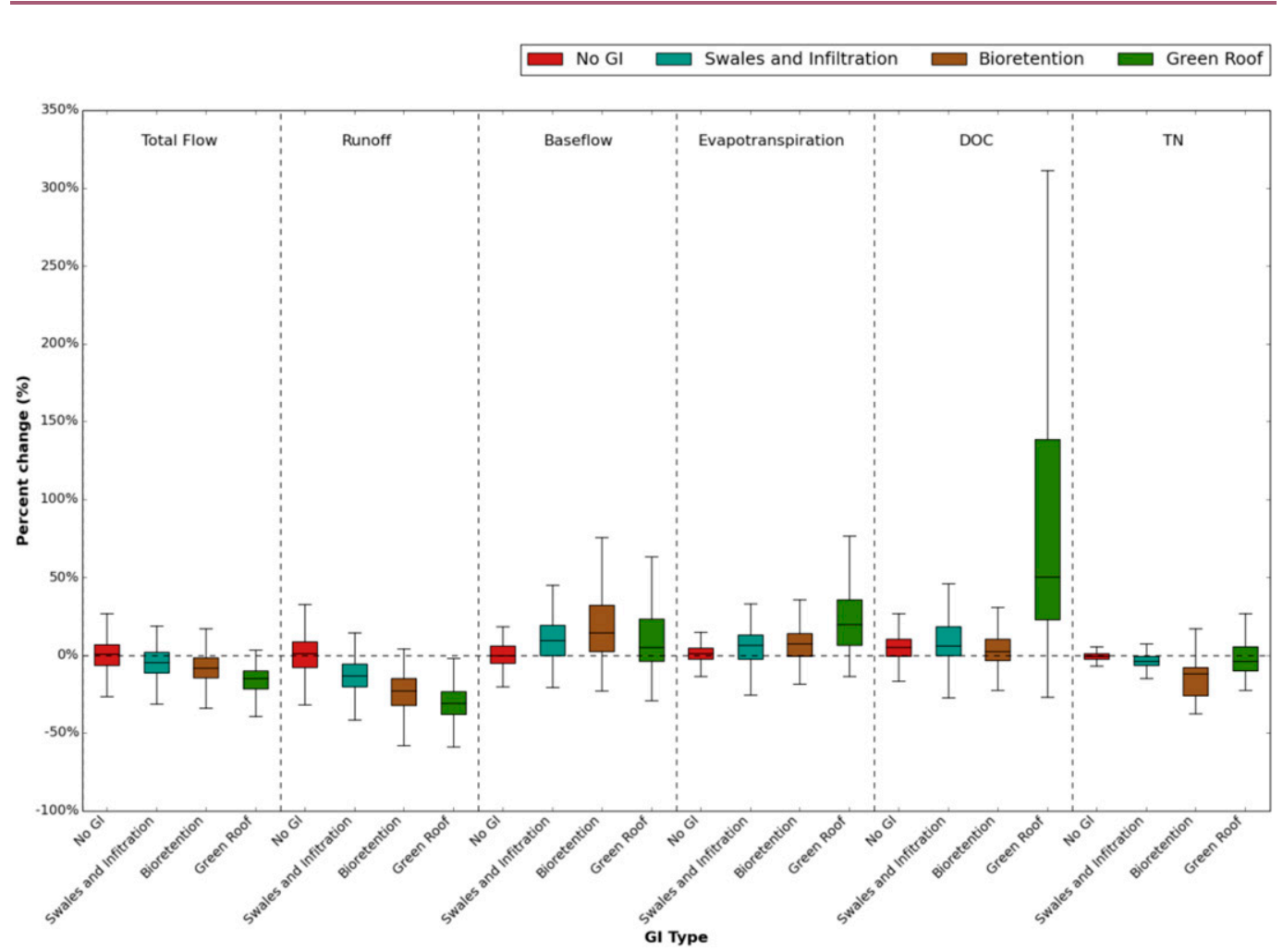

Figure 24. Simulated changes in future total flow, runoff, base flow, ET, DOC, and TN yield relative to historic climate by $\mathrm{GI}$ type.

This study uses the RHESSys model, with simple enhancements to the code, to examine the potential effects of climate change on the performance of stormwater management using urban GI (bioretention, swales, and green roofs) in different archetypal urban blocks (based on density and pattern). Comparison of simulations in this study to the scientific literature suggests that RHESSys is a reasonable tool for evaluating GI effects on runoff, DOC and N storages, and fluxes for urban sites.

Future climate change is expected to vary regionally within the United States. There is also variability in projected changes among climate models, particularly for local-scale precipitation, which is the key driver of stormwater runoff. Simulation results in this study suggest that GI can reduce surface runoff and increase ET. In cases where scenarios suggest increased precipitation and runoff, results suggest GI provides substantial mitigation of these increases. However, performance under future climate is at risk of not achieving current levels of protection.

GI can also help mitigate potential increases in $\mathrm{N}$ loads, though not under all situations. Green roof designs in particular are likely to increase N loads if fertilized; however, green roofs also provide the greatest potential mitigation of urban heat island effects. RHESSys does not simulate erosion, sediment transport, or phosphorus export (which depends in large part on sediment transport), so the model is not applicable to these water quality concerns. Erosion in urban settings is largely driven by site disturbances and the effect of increased impervious cover and 
Earth Interactions - Volume 22 (2018) - Paper No. 13 • Page 32

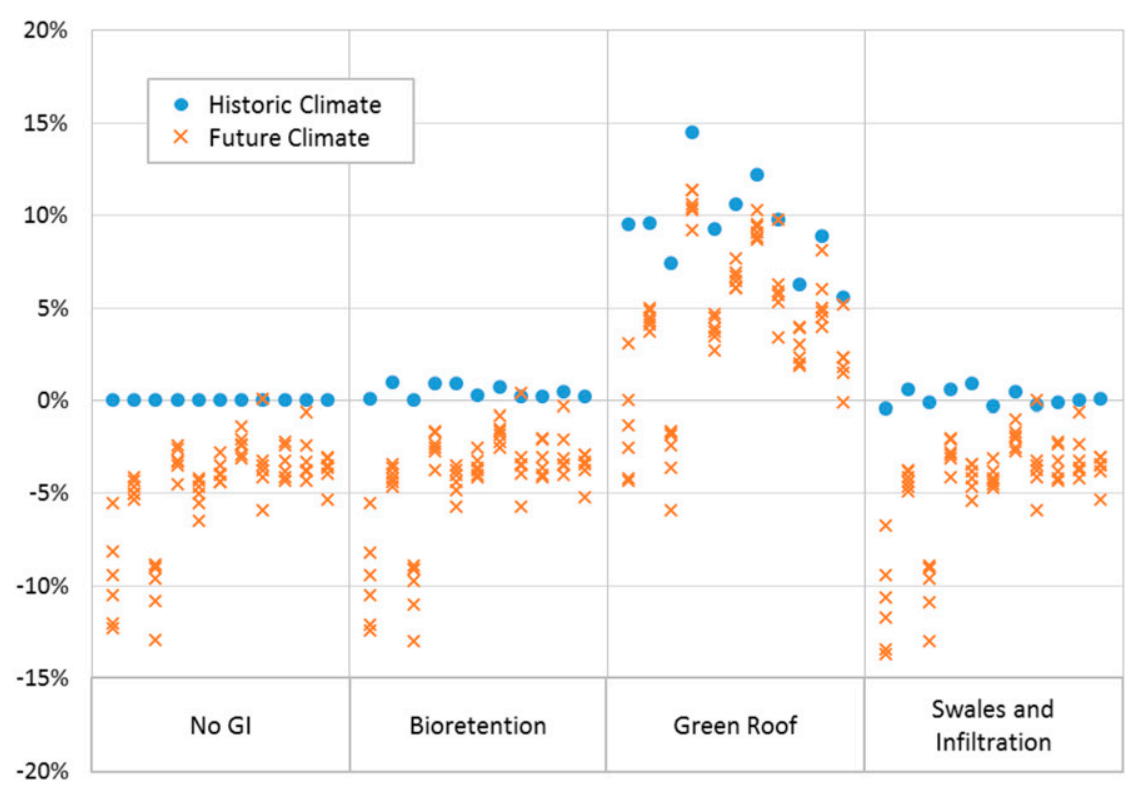

Figure 25. Projected changes in carbon storage for single-family residential AUS. Results for each BMP are shown in alphabetical city order for Albuquerque (NM), Atlanta (GA), Boulder (CO), Cleveland (OH), Dallas (TX), Los Angeles (CA), Minneapolis (MN), New Orleans (LA), Portland (OR), Tampa (FL), and Worcester (MA).

hydromodification on channel stability. Those processes are better addressed through detailed hydraulic channel routing models.

In sum, GI can be a useful component of a stormwater management portfolio that is resilient to climate change. Results of the analyses presented here show GI has benefits in a range of urban settings and climatic conditions, both for controlling pollutant loads as well as providing carbon storage and helping to mitigate local atmospheric warming. However, practitioners need to recognize that changes in climate may reduce the performance of some GI components.

In some locations, sizing criteria for urban BMPs, including GI, may need to change to address future climate. To respond to climate change, infrastructure design should emphasize greater flexibility and robustness to a range of plausible but uncertain future conditions. Most GI components require frequent maintenance, which would provide the opportunity for adaptive changes in design over time in response to observed climate trends-but only if site plans allow sufficient space for any needed expansions.

Acknowledgments. We thank Dr. Lawrence Band and Dr. Brian Miles for providing the RHESSys code and workflows as well as providing help and advice on RHESSys implementation. The writers also thank Seth McGinnis of the National Center for Atmospheric Research (NCAR) for processing the NARCCAP output into change statistics for use in the watershed modeling, as well as the NARCCAP and BCSD project teams. NCAR is supported by the National Science Foundation. The writers acknowledge the 


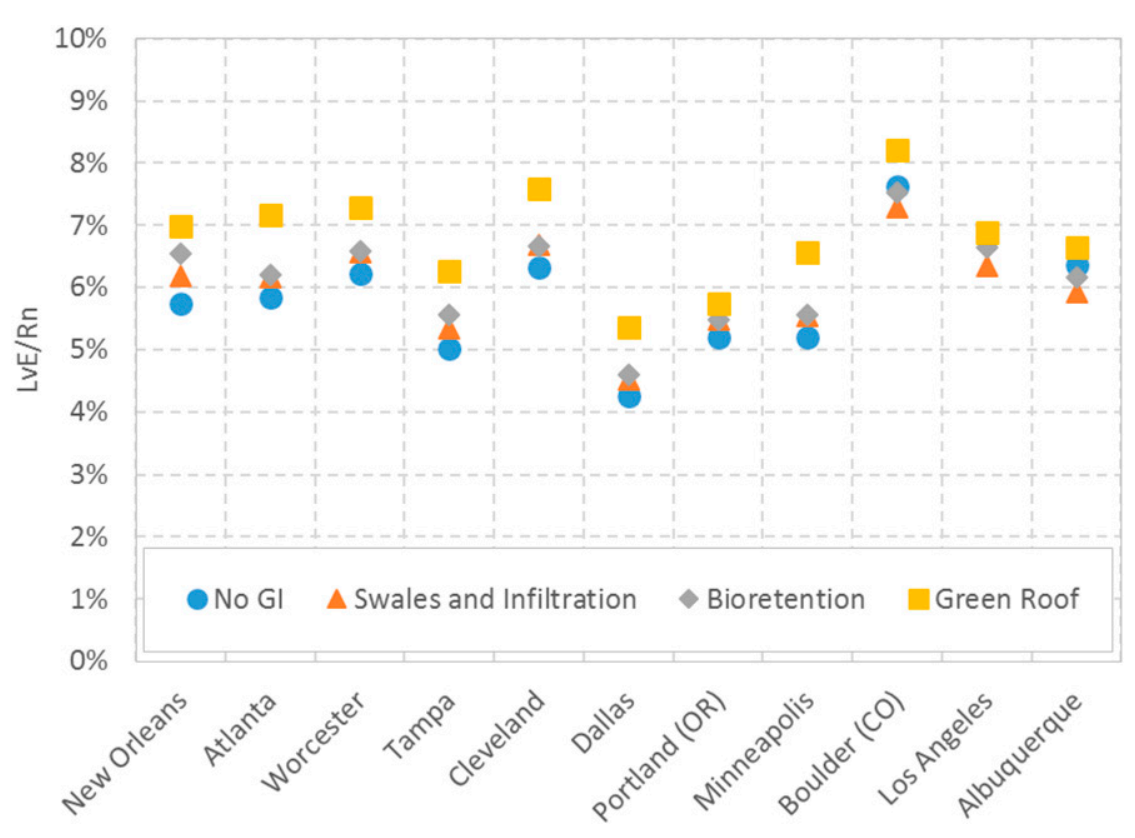

Figure 26. Average percentage of incoming radiation converted to latent heat.

modeling groups, the Program for Climate Model Diagnosis and Intercomparison (PCMDI) and the WCRP's Working Group on Coupled Modeling (WGCM), for their roles in making available the WCRP CMIP3 multimodel dataset. Support of this dataset is provided by the Office of Science, U.S. Department of Energy. Funding for this work was provided by the U.S. Environmental Protection Agency, Office of Research and Development. Authors SS and JBB were supported via Work Assignment 4-13 under Contract EP-C-12-060 to Tetra Tech, Inc. Authors TEJ and CMC are employees of the U.S. EPA Office of Research and Development. The views expressed in this paper represent those of the authors and do not necessarily reflect the views or policies of the U.S. Environmental Protection Agency.

\section{Appendix: Model Abbreviations}

\section{CGCM3}

\section{Third Generation Coupled Global Climate Model}

http://www.ec.gc.ca/ccmac-cccma/default.asp?lang=En\&n=4A642EDE-1

\section{HadCM3}

Hadley Centre Coupled Model, version 3

http://www-pcmdi.llnl.gov/ipcc/model_documentation/HadCM3.htm

\section{GFDL}

Geophysical Fluid Dynamics Laboratory GCM 
Earth Interactions - Volume 22 (2018) • Paper No. 13 • Page 34

http://www-pcmdi.llnl.gov/ipcc/model_documentation/GFDL-cm2.htm

CCSM

Community Climate System Model

http://www-pcmdi.llnl.gov/ipcc/model_documentation/CCSM3.htm

CRCM

Canadian Regional Climate Model

http://www.ec.gc.ca/ccmac-cccma/default.asp?lang=En\&n=4A642EDE-1

RCM3

Regional Climate Model, version 3

http://users.ictp.it/ pubregcm/RegCM3/

HRM3

Hadley Regional Model 3

http://precis.metoffice.com/

WRFG

Weather Research and Forecasting Model, using the Grell convection scheme http://www.wrf-model.org/index.php

GFDL hi res

Geophysical Fluid Dynamics Laboratory 50-km global atmospheric time slice http://www-pcmdi.llnl.gov/ipcc/model_documentation/GFDL-cm2.htm

\section{References}

Arisz, H., and B. C. Burrell, 2006: Urban drainage infrastructure planning and design considering climate change. 2006 IEEE EIC Climate Change Conf., Ottawa, Ontario, Canada, IEEE, 1-9, https://doi.org/10.1109/EICCCC.2006.277251.

Arnold, C. L., Jr., and C. J. Gibbons, 1996: Impervious surface coverage: The emergence of a key environmental indicator. J. Amer. Plann. Assoc., 62, 243-258, https://doi.org/10.1080/ 01944369608975688.

BES, 2011: Physical, chemical, and biological properties of forest and home lawn soils. Baltimore Ecosystem Study Rep. BES_0584/11, https://besiter.org/metacat_harvest_attribute_level_eml/ html_metadata/bes_584.asp.

Bhaskar, A. S., and C. Welty, 2012: Water balances along an urban-to-rural gradient of metropolitan Baltimore, 2001-2009. Environ. Eng. Geosci., 18, 37-50, https://doi.org/10.2113/ gseegeosci.18.1.37.

Carey, R. O., and Coauthors, 2012: A review of turfgrass fertilizer management practices: Implications for urban water quality. Hortic. Tech., 22, 280-291.

Del Grosso, S. J., A. R. Mosier, W. J. Parton, and D. S. Ojima, 2005: DAYCENT model analysis of past and contemporary soil $\mathrm{N}_{2} \mathrm{O}$ and net greenhouse gas flux for major crops in the USA. Soil Tillage Res., 83, 9-24, https://doi.org/10.1016/j.still.2005.02.007.

— D. S. Ojima, W. J. Parton, E. Stehfest, M. Heistemann, B. DeAngelo, and S. Rose, 2009: Global scale DAYCENT model analysis of greenhouse gas emissions and mitigation 
strategies for cropped soils. Global Planet. Change, 67, 44-50, https://doi.org/10.1016/ j.gloplacha.2008.12.006.

Dow, C. L., and D. R. DeWalle, 2000: Trends in evaporation and Bowen ratio on urbanizing watersheds in eastern United States. Water Resour. Res., 36, 1835-1843, https://doi.org/ 10.1029/2000WR900062.

Driscoll, C. T., and Coauthors, 2015: Green infrastructure: Lessons from science and practice. Science Policy Exchange Rep., 32 pp., https://s3.amazonaws.com/nyclimatescience.org/ gi_report_surdna_6_29_15_final.pdf.

Easterling, W. E., N. J. Rosenberg, M. S. McKenney, C. A. Jones, P. T. Dyke, and J. R. Williams, 1992: Preparing the erosion productivity impact calculator (EPIC) model to simulate crop response to climate change and the direct effects of $\mathrm{CO}_{2}$. Agric. For. Meteor., 59, 17-34, https://doi.org/10.1016/0168-1923(92)90084-H.

Filipovic, A., J. Rogan, A. Elmes, and D. Martin, 2016: Modeling hydrological ecosystem services of juvenile trees in Worcester, Massachusetts. The Association of American Geographers Annual Meeting, San Francisco, CA, AAG, Poster 52, http://www.itreetools.org/resources/ reports/HydroWorcesterMA_afilipovic_AAGPoster.pdf.

Georgescu, M., P. E. Morefield, B. G. Bierwagen, and C. P. Weaver, 2014: Urban adaptation can roll back warming of emerging megapolitan regions. Proc. Natl. Acad. Sci. USA, 111, 2909-2914, https://doi.org/10.1073/pnas.1322280111.

Gill, S. E., J. F. Handley, A. R. Ennos, and S. Pauleit, 2007: Adapting cities for climate change: The role of the green infrastructure. Built Environ., 33, 115-133, https://doi.org/10.2148/ benv.33.1.115.

Gregory, J. H., M. D. Dukes, P. H. Jones, and G. L. Miller, 2006: Effect of urban soil compaction on infiltration rate. J. Soil Water Conserv., 61, 117-124.

Groffman, P. M., N. L. Law, K. T. Belt, L. E. Band, and G. T. Fisher, 2004: Nitrogen fluxes and retention in urban watershed ecosystems. Ecosystems, 7, 393-403, https://doi.org/10.1007/ s10021-003-0039-x.

— nomena (hotspots and hot moments) in denitrification models. Biogeochemistry, 93, 49-77, https://doi.org/10.1007/s10533-008-9277-5.

Hamlet, A. F., and D. P. Lettenmaier, 2007: Effects of 20th century warming and climate variability on flood risk in the western U.S. Water Resour. Res., 43, W06427, https://doi.org/10.1029/ 2006WR005099.

Hewlett, J. D., 1982: Principles of Forest Hydrology. University of Georgia Press, 183 pp.

IPCC, 2014: Summary for policymakers. Climate Change 2014: Impacts, Adaptation, and Vulnerability. Part A: Global and Sectoral Aspects. C. B. Field et al., Eds., Cambridge University Press, 1-32, https://www.ipcc.ch/pdf/assessment-report/ar5/wg2/ ar5_wgII_spm_en.pdf.

Jha, M., J. G. Arnold, P. W. Gassman, F. Giorgi, and R. R. Gu, 2006: Climate change sensitivity assessment on Upper Mississippi River Basin streamflows using SWAT. J. Amer. Water Resour. Assoc., 42, 997-1015, https://doi.org/10.1111/j.1752-1688.2006.tb04510.x.

Johnson, T., and Coauthors, 2015: Modeling streamflow and water quality sensitivity to climate change and urban development in 20 U.S. watersheds. J. Amer. Water Resour. Assoc., 51, 1321-1341, https://doi.org/10.1111/1752-1688.12308.

Kleerekoper, L., M. van Esch, and T. B. Salcedo, 2012: How to make a city climate-proof, addressing the urban heat island effect. Resour. Conserv. Recycl., 64, 30-38, https://doi.org/ 10.1016/j.resconrec.2011.06.004.

Li, C., J. Aber, F. Stange, K. Butterbach-Bahl, and H. Papen, 2000: A process-oriented model of $\mathrm{N}_{2} \mathrm{O}$ and $\mathrm{NO}$ emissions from forest soils: 1. Model development. J. Geophys. Res., 105, 4369-4384, https://doi.org/10.1029/1999JD900949.

Liu, S., Y. Wei, W. M. Post, R. B. Cook, K. Schaefer, and M. M. Thornton, 2014: NACP MsTMIP: Unified North American soil map. Oak Ridge National Laboratory Distributed 
Earth Interactions - Volume 22 (2018) • Paper No. 13 • Page 36

Active Archive Center, accessed 3 February 2016, https://doi.org/10.3334/ORNLDAAC/ 1242.

Mearns, L. O., W. J. Gutowski, R. Jones, R. Leung, S. McGinnis, A. Nunes, and Y. Qian, 2009: A regional climate change assessment program for North America. Eos, Trans. Amer. Geophys. Union, 90, 311, https://doi.org/10.1029/2009EO360002.

_ - and Coauthors, 2013: Climate change projections of the North American Regional Climate Change Assessment Program (NARCCAP). Climatic Change, 120, 965-975, https://doi.org/ 10.1007/s10584-013-0831-3.

Medlyn, B. E., and Coauthors, 2001: Stomatal conductance of forest species after long-term exposure to elevated $\mathrm{CO}_{2}$ concentration: A synthesis. New Phytol., 149, 247-264, https:// doi.org/10.1046/j.1469-8137.2001.00028.x.

Miles, B. C., 2014: Small-scale residential stormwater management in urbanized watersheds: A geoinformatics-driven ecohydrology modeling approach. Ph.D. dissertation, Dept. of Geography, University of North Carolina at Chapel Hill, 216 pp.

— Urban variable source area and watershed capacitance. Hydrol. Processes, 29, 2268-2274, https://doi.org/10.1002/hyp.10448.

Milesi, A., S. W. Running, C. D. Elvidge, J. B. Dietz, B. J. Tuttle, and R. R. Nemani, 2005: Mapping and modeling the biogeochemical cycling of turf grasses in the United States. Environ. Manage., 36, 426-438, https://doi.org/10.1007/s00267-004-0316-2.

Miller, D. A., and R. A. White, 1998: A conterminous United States multilayer soil characteristics dataset for regional climate and hydrology modeling. Earth Interact., 2, 1-26, https://doi.org/ 10.1175/1087-3562(1998)002<0001:ACUSMS >2.3.CO;2.

Mittman, T., L. E. Band, T. Hwang, and M. L. Smith, 2012: Distributed hydrologic modeling in the suburban landscape: Assessing parameter transferability from gauged reference catchments. J. Amer. Water Resour. Assoc., 48, 546-557, https://doi.org/10.1111/ j.1752-1688.2011.00636.x.

Monteith, J. L., 1965: Evaporation and the environment. Symp. Soc. Explor. Biol., 19, 205-234.

Nakicenovic, N., and Coauthors, 2000: Special Report on Emissions Scenarios. Cambridge University Press, 599 pp., http://www.grida.no/climate/ipcc/emission/.

NRCS, 2005: Bioswales. Natural Resources Conservation Service Rep., 2 pp., https://www.nrcs. usda.gov/Internet/FSE_DOCUMENTS/nrcs144p2_029251.pdf.

Pataki, D. E., and Coauthors, 2011: Coupling biogeochemical cycles in urban environments: Ecosystem services, green solutions, and misconceptions. Front. Ecol. Environ., 9, 27-36, https://doi.org/10.1890/090220.

Pielke, R. A., Sr., 2013: Mesoscale Meteorological Modeling. 3rd ed. Academic Press, 760 pp.

Pitt, R., S. E. Chen, and S. Clark, 2002: Compacted urban soils effects on infiltration and bioretention stormwater control designs. Ninth Int. Conf. on Urban Drainage, Portland, Oregon, ASCE, 21 pp., https://doi.org/10.1061/40644(2002)14.

Pouyat, R. V., I. D. Yesilonis, and D. J. Nowak, 2006: Carbon storage in urban soils in the United States. J. Environ. Qual., 35, 1566-1575, https://doi.org/10.2134/jeq2005.0215.

Schwede, D. B., and G. G. Lear, 2014: A novel hybrid approach for estimating total deposition in the United States. Atmos. Environ., 92, 207-220, https://doi.org/10.1016/j.atmosenv.2014.04.008.

Shields, C., and C. Tague, 2015: Ecohydrology in semiarid urban ecosystems: Modeling the relationship between connected impervious area and ecosystem productivity. Water Resour. Res., 51, 302-319, https://doi.org/10.1002/2014WR016108.

Sickman, J. O., M. J. Zanoli, and H. L. Mann, 2007: Effects of urbanization on organic carbon loads in the Sacramento River, California. Water Resour. Res., 43, W11422, https://doi.org/ 10.1029/2007WR005954.

Smith, R. M., and S. S. Kaushal, 2015: Carbon cycle of an urban watershed: Exports, sources, and metabolism. Biogeochemistry, 126, 173-195, https://doi.org/10.1007/ s10533-015-0151-y. 


\section{Earth Interactions • Volume 22 (2018) • Paper No. 13 • Page 37}

Tague, C. L., and L. E. Band, 2004: RHESSys: Regional Hydro-Ecologic Simulation System-An object-oriented approach to spatially distributed modeling of carbon, water, and nutrient cycling. Earth Interact., 8, 1-42, https://doi.org/10.1175/1087-3562(2004)8<1:RRHSSO >2.0.CO;2.

Taha, H., 1997: Urban climates and heat islands: Albedo, evapotranspiration, and anthropogenic heat. Energy Build., 25, 99-103, https://doi.org/10.1016/S0378-7788(96)00999-1.

U.S. Census Bureau, 2010: 2010 Census urban area facts. United States Census Bureau, http:// www.census.gov/geo/reference/ua/uafacts.html.

USDA, 1986: Urban hydrology for small watersheds. USDA Tech. Release 55, 164 pp., https:// www.nrcs.usda.gov/Internet/FSE_DOCUMENTS/stelprdb1044171.pdf.

U.S. EPA, 2007: Reducing stormwater costs through low impact development (LID) strategies and practices. U.S. EPA Rep. EPA 841-F-07-006, 37 pp.

- 2013: Watershed modeling to assess the sensitivity of streamflow, nutrient, and sediment loads to potential climate change and urban development in 20 U.S. watersheds. U.S. EPA Rep. EPA/600/R-12/058F, 196 pp.

VWRRC, 2011: Bioretention version 1.9. Virginia DEQ Stormwater Design Specification 9, http:// www.vwrrc.vt.edu/swc/NonPBMPSpecsMarch11/VASWMBMPSpec9BIORETENTION.html.

Walsh, C. J., A. H. Roy, J. W. Feminella, P. D. Cottingham, P. M. Groffman, and R. P. Morgan II, 2005: The urban stream syndrome: Current knowledge and the search for a cure. J. N. Amer. Benthol. Soc., 24, 706-723, https://doi.org/10.1899/04-028.1.

Wang, J., T. A. Endreny, and D. J. Nowak, 2008: Mechanistic simulation of tree effects in an urban water balance model. J. Amer. Water Resour. Assoc., 44, 75-85, https://doi.org/10.1111/ j.1752-1688.2007.00139.x.

Wigmosta, M., L. Vail, and D. Lettenmaier, 1994: A distributed hydrology-vegetation model for complex terrain. Water Resour. Res., 30, 1665-1679, https://doi.org/10.1029/ 94WR00436.

Yang, Y., 2013: Studying soil moisture and land-to-water carbon export in urbanized coastal areas using remotely sensed data and a regional hydro-ecological model. Ph.D. dissertation, University of Massachusetts, Boston, $180 \mathrm{pp}$.

Earth Interactions is published jointly by the American Meteorological Society, the American Geophysical Union, and the Association of American Geographers. For information regarding reuse of this content and general copyright information, consult the AMS Copyright Policy (www.ametsoc.org/PUBSReuseLicenses). 